(i)

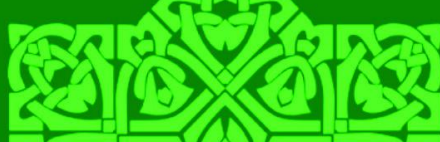
tह

Muhammad Yusuf, Baharuddin, Mardan The Quranic Hermeneutics Approach to Gender Equality in Amina Wadud Muhsin's View

A. Zamakhsyari Baharuddin التظاهر بالشعار ات القومية في شعيرة الحج و العمرة

Andi Muhammad Ridwan, Baso Pallawagau Falsafah Al-Wujudiyyah Al-Sufiyyah: Asluha Al-Dini wa Manqif Al-Ulama Minha

Muhammad Widus Sempo, Norita Binti Md Norwawi, Hasyim Haddade, Yousuf Mahbubul Islam, Noorhayati Binti Hasyim Unbelievers' Mental Model and Behavioural Disorders Based on Their Queries in The Al-Baqarah Chapter

Sri Sunantri, Achmad Abubakar, Kamaluddin Abu Nawas, Firdaus Methodology of Interpretation of Muhammad Amin Al-Syinqiti

Amirullah, Andi Achruh AB. Pasinringi, Rahmawansyah Sahib The Transformation of The Muamalah Fiqh Akad at Saga Abepura-Papua Mall During The Covid 19 Pandemic

Irwan Misbach Siri'Na Pacce Culture in Retailer Based on Islamic Perspective Business Ethics

Abd. Rahman R Family Resilience in Islamic Perspective (A Case Study of Parent and Child Interaction Behavior in The District of Somba Opu Gowa)

Vol. 20 No. $2 / 2020$ 


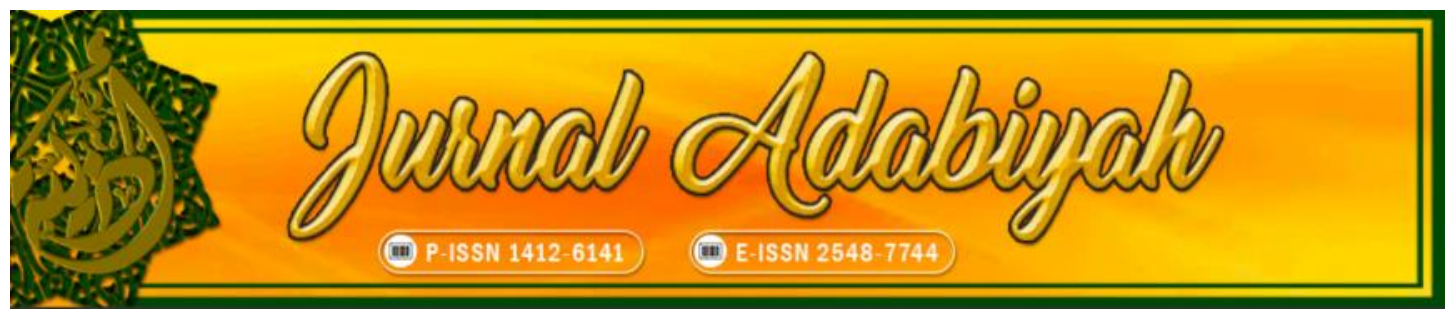

Theme: Islamic Studies

VOLUME 20 NO. 2 DECEMBER 2020

\section{EDITOR-IN-CHIEF}

Barsihannor, Alauddin State Islamic University, Indonesia

\section{INTERNATIONAL EDITORIAL BOARD}

Nuri Emmiyati, Alauddin State Islamic University, Indonesia

Minako Sakai, Australian National University (ANU), Australia

Abd Rauf Muhammad Amin, Fakulti Syariah Kupu SB Brunei Darussalam, Brunei Darussalam

Muhammad Widus Sempo, Universiti Sains Islam Malaysia, Malaysia

Salih Yousif Sharaf Mohamed, Al-Gazera University, Sudan

Aishah Waenaha Waemamah, Academy of Islamic and Arabic Studies Princess of Naradhiwas University - Thailand, Thailand

\section{EXECUTIVE EDITOR}

Umar Thamrin, Alauddin State Islamic University, Indonesia

\section{MANAGING EDITOR}

Nasrum, Alauddin State Islamic University, Indonesia

\section{EDITORS}

Rosmah Tami, Alauddin State Islamic University, Indonesia Haniah Haniah, Alauddin State Islamic University, Indonesia Zaenal Abidin, Alauddin State Islamic University, Indonesia

Awaluddin Syamsu, Universitas Muslim Indonesia

Ahmadi Usman, UIN Syarif Hidayatullah Jakarta, Indonesia

Baso Pallawagau, Alauddin State Islamic University, Indonesia

Muhammad Azwar, UIN Syarif Hidayatullah Jakarta, Indonesia

Muh. Saleh Syamsuri, Alauddin State Islamic University, Indonesia

Andi Satrianingsih, Muhammadiyah University, Indonesia

Syahruni - Junaid, Alauddin State Islamic University, Indonesia

Rabiatul Adawiah, Majene Islamic State College, West Sulawesi, Indonesia, Indonesia

Chusnul Chatimah Asmad, Alauddin State Islamic University, Indonesia

Nur Arifin, Alauddin State Islamic University, Indonesia

\section{IT SUPPORT}

Taufiq Mathar, Alauddin State Islamic University, Indonesia

\section{LANGUAGE ADVISOR}

Kustiwan Syarief, UIN Syarif Hidayatullah Jakarta, Indonesia Muh. Saleh Syamsuri, Alauddin State Islamic University, Indonesia

\section{COVER DESIGNER}

Nur Arifin 


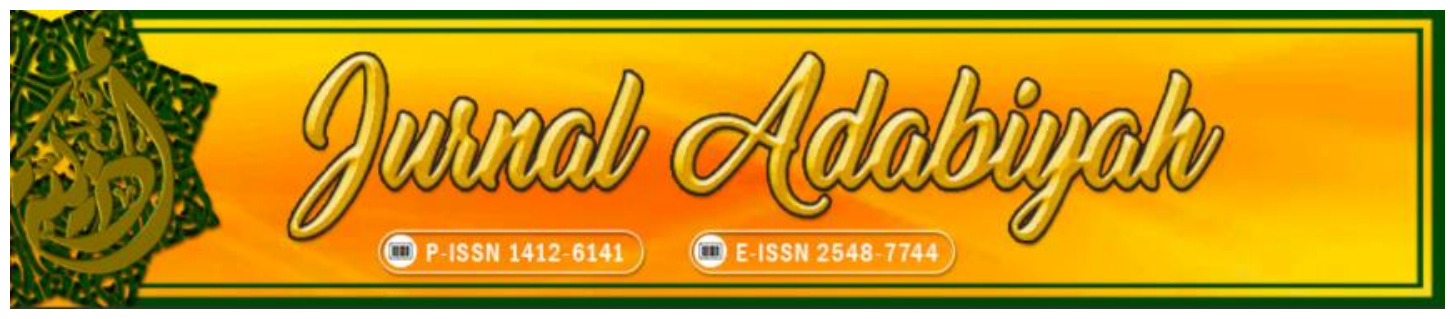

\section{Jurnal Adabiyah:}

This journal receives a national accreditation from Ministry of Research, Technology, and Higher Education Republic of Indonesia, Nomor 10/E/KPT/2019 on April 4, 2019 with the SINTA score: S2.

The Journal has been published by the Faculty of Adab and Humanity of Alauddin State Islamic University, Makassar, since 1997 and has been online since 2016 with the main themes on Humanities and Islamic Studies with the emphasis on interdisciplinary and intertextuality approach.

This journal are published twice a year, on June and December. The themes related to Islamic Studies are textual studies, scriptural traditions, Islamic law, and theology; and those related to Humanities are language, literature, history, and culture.

The journal of Humanities and Islamic Studies will provide the online collection of articles from 1997 up to now. The most updated information can be found on the website. 


\section{Table of Contents}

Muhammad Yusuf, Baharuddin, Mardan

214-237

The Quranic Hermeneutics Approach to Gender Equality in Amina Wadud Muhsin's View

A. Zamakhsyari Baharuddin

التظاهربالشعارات القومية في شعيرة الحج والعمبرة

261-285

Andi Muhammad Ridwan, Baso Pallawagau

Falsafah Al-Wujudiyyah Al-Sufiyyah: Asluha Al-Dini wa Mauqif AlUlama Minha

Muhammad Widus Sempo, Norita Binti Md Norwawi, Hasyim Haddade, Yousuf Mahbubul Islam, Noorhayati Binti Hasyim ................... 286-299 Queries in The Al-Baqarah Chapter

Sri Sunantri, Achmad Abubakar, Kamaluddin Abu Nawas, Firdaus. 300-319 Methodology of Interpretation of Muhammad Amīn Al-Syinqiti

Amirullah, Andi Achruh AB. Pasinringi, Rahmawansyah Sahib

The Transformation of The Muamalah Fiqh Akad at Saga Abepura-Papua Mall During The Covid 19 Pandemic

Irwan Misbach

Siri' Na Pacce Culture in Retailer Based on Islamic Perspective Business Ethics

Abd Rahman R

Family Resilience in Islamic Perspective (A Case Study of Parent and Child Interaction Behavior in The District of Somba Opu Gowa) 


\title{
فلسفة الوجودية الصهوفية؛ أصلها الديني وموقف العلماء منها
}

\section{Andi Muhammad Ridwan', Baso Pallawagau}

Al-Azhar University, Cairo

Universitas Islam Negeri Alauddin Makassar, Indonesia ${ }^{2}$

Email: andiridwan011182@gmail.com ${ }^{1}$, baso.pallawagau@uin-alauddin.ac.id ${ }^{2}$

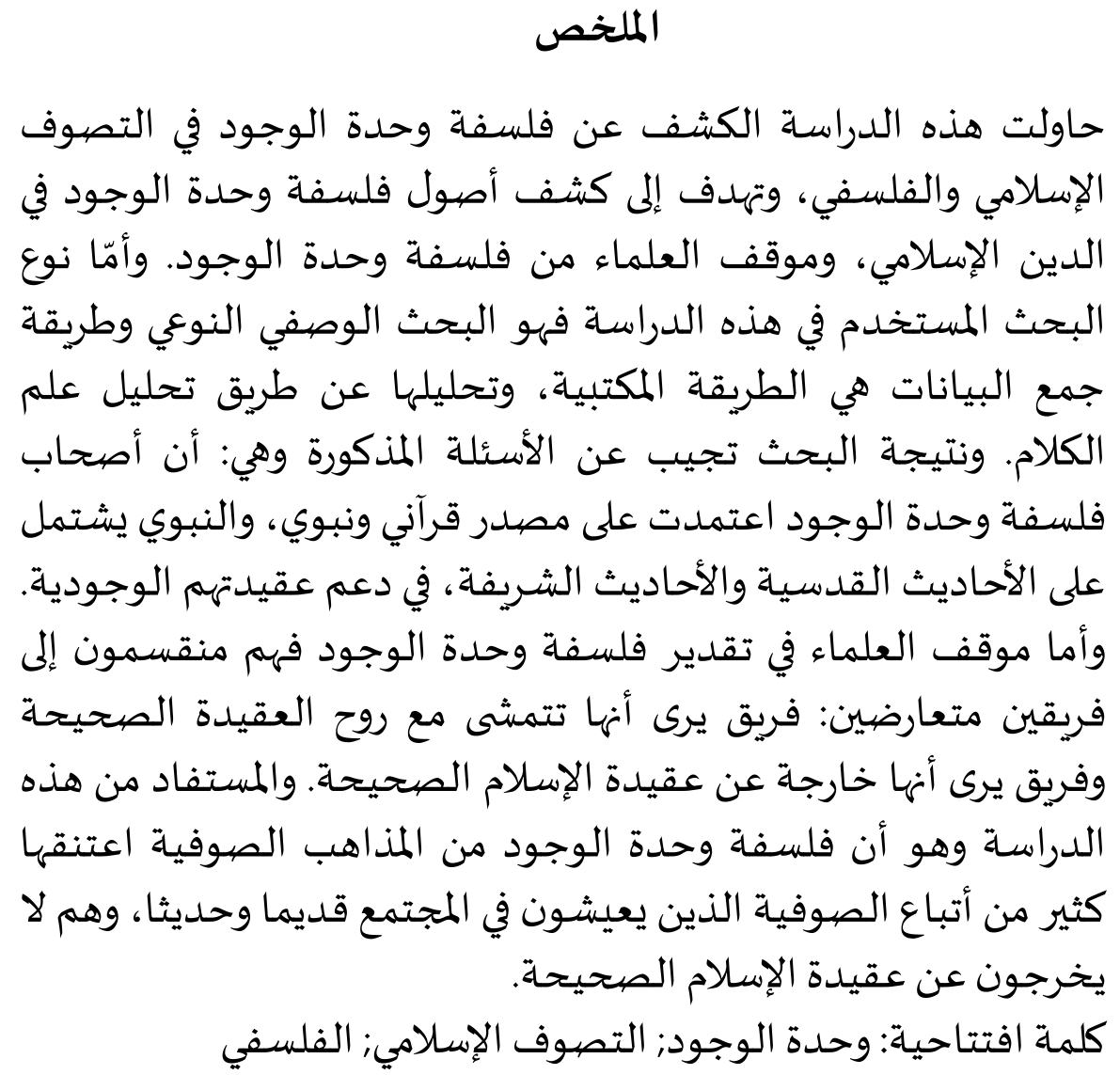

\begin{abstract}
This research reveals the philosophy of pantheism (wahdatul wujud) in Islamic tasawwuf and philosophical tasawwuf with the aim of exploring the basic philosophy of pantheism in Islam and how the ulama's attitude towards the philosophy of pantheism. This research used descriptive qualitative, library research data methods (library research) and data analysis using kalam science analysis. The results showed that: Adherents of the philosophy of pantheism were guided by the Qur'an and the Hadith
\end{abstract}


of the Prophet, both the qudsi and nabaw's hadits of the prophet in supporting their faith. the attitude of the scholar in assessing pantheism, they are divided into two groups with different opinions. Groups who argue that the philosophy of pantheism is in accordance with the correct Islamic creed, and groups who argue that this philosophy deviates from Islamic creeds. The implication of this research shows that the philosophy of pantheism is one of the Sufism schools adopted by many Sufis who are present in society, both traditional and modern societies. They actually do not deviate from the true Islamic creed.

Keywords: Pantheism; Islamic Tasawwuf; Philosophical Tasawwuf

\begin{abstract}
Abstrak
Penelitian ini mengungkap filsafat panteisme (wahdatul wujud) di dalam tasawwuf Islam dan tasawwuf filosofis, dengan tujuan menggali dasar filsafat panteisme di dalam Islam dan bagaimana sikap ulama terhadap filsafat panteisme. Jenis penelitian menggunakan deskriptif kualitatif, metode pengumpulan data bersifat penelitian kepustakaan (library research) dan analisis data mempergunakan analisis ilmu kalam. Hasil penelitian menunjukkan bahwa: Penganut filsafat panteisme berpedoman pada al-Qur'an dan Hadis Nabi saw., baik hadis qudsi maupun hadis nabawi dalam menyokong akidah mereka. Adapun sikap ulama di dalam menilai filsafat panteisme, mereka terbagi dua golongan yang berbeda pendapat. Ada golongan yang berpendapat bahwa filsafat panteisme sesuai dengan akidah Islam yang benar, dan ada golongan yang berpendapat bahwa filsafat tersebut melenceng dari akidah Islam. Implikasi penelitian menunjukkan bahwa filsafat panteisme merupakan salah satu aliran tasawwuf yang dianut oleh banyak kaum sufi yang hadir di masyarakat, baik masyarakat tradisional maupun masyarakat moderen. Mereka sebenarnya tidak melenceng dari akidah Islam yang benar.
\end{abstract}

Kata kunci: Wahdatul Wujud; Tasawwuf Islam; Tasawwuf Filosofis.

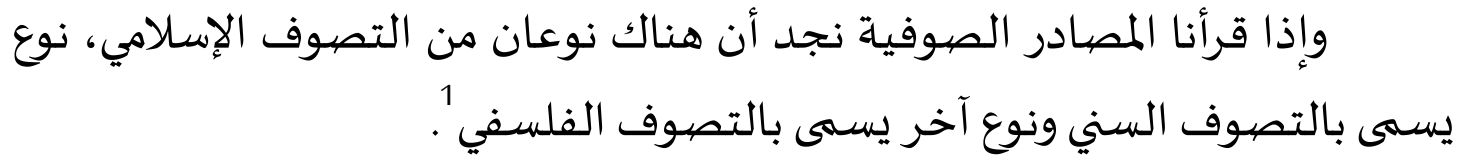

1 Abul Yazid Al-'Ajami, 'Al-Tauhid Baena Al-Tasawwuf Al-Sunni Wa Al-Tasawwuf AlFalsafi (Isyarat Wa Dilalat)', Hauliyah, 14 (1996), 99-138. 
فالتصوف السني هو قطع عقبات النفس، والتخلص إلى حرية التقوى،

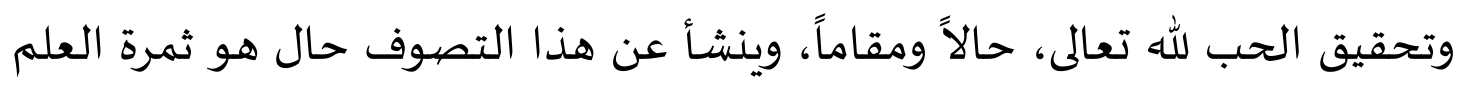

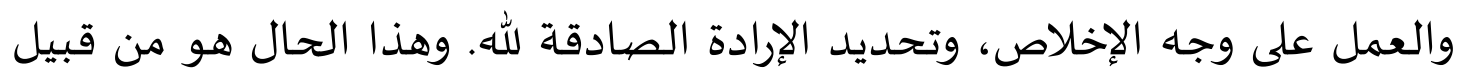

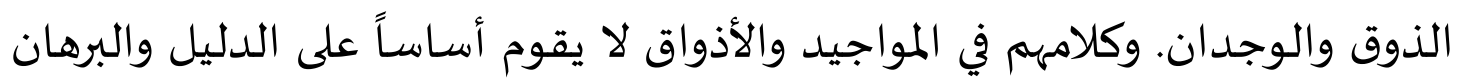
كما هو الحال في الفلسفة البحتة، وإنما على المكاشفة والعيد والعيان. أما التصوف الفلسفي فهو التصوف الذي يمتزج فيه الأذواق الصوفية بالنظر وإنها

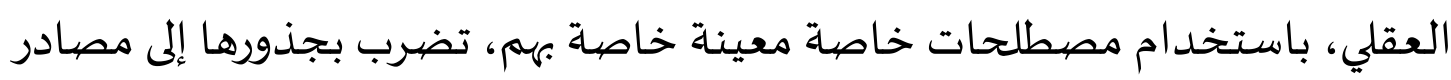

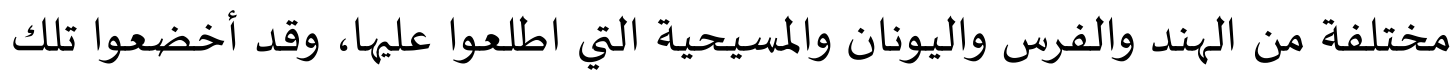

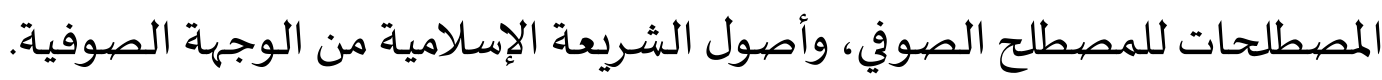

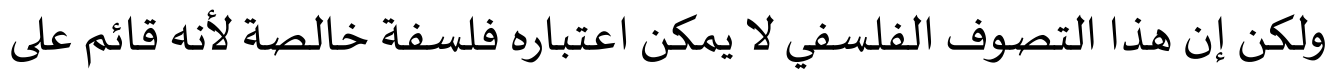

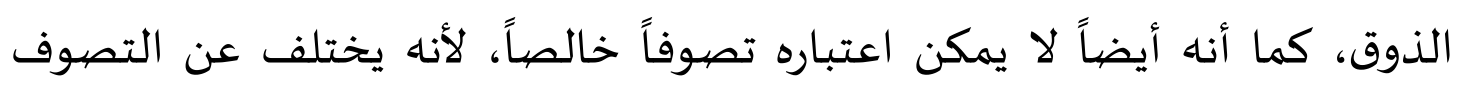

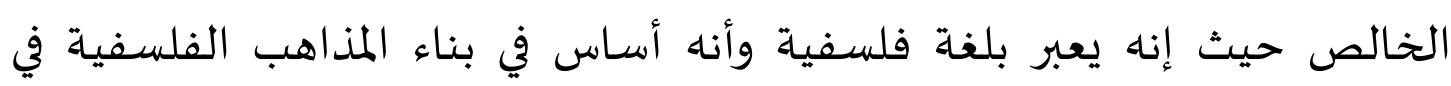

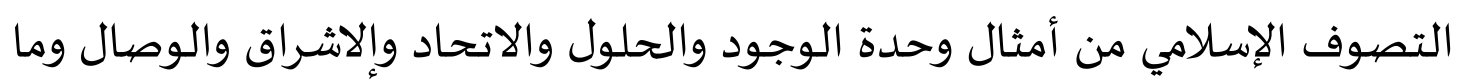
إلى ذلك.

إن نظرية وحدة الوجود إحدى نطريات التصوف الفلسفي، وهي نظرية

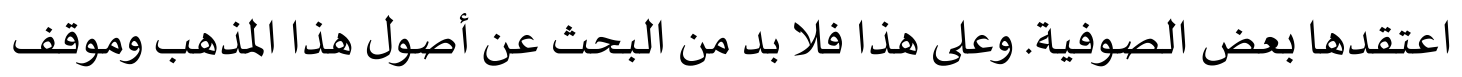
العلماء تجاهه، لنعرف مدى أصالة وشرعية هذه النظرية في التعاليم الإسلامية. وهيدف هذا البحث إلى معرفة أصول مذهب وحدة الوجود في في التصدوف

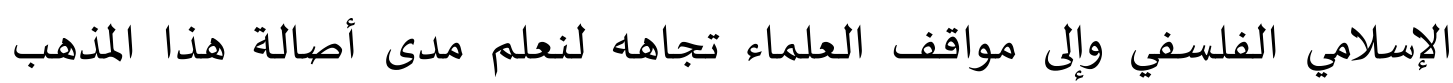
وموافقته مع روح الدين الإسلامي. وفيما يلي سوف نتكلم عن فلسفة وحدة الوجود كنظرية فلسفية وجدات في الاسلي إطار التصوف الإسلامي، اعتقدها كثير من أتباع الصيوفية، لنتعرف مدى وند أصالتها وشرعيتها في تعليم الدين الإسلامي. 


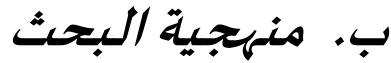

نوع البحث المستخدم في هذه الدراسة فهو البحث الوصفي النوعي، والطريقة

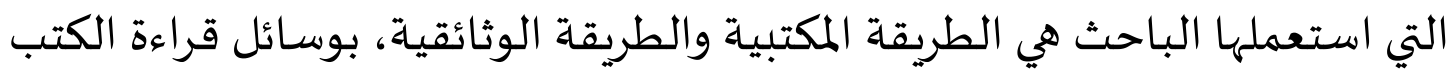
والمقالات المتنوعة المتعلقة بهذه الدراسـة.

ومصدر البيانات يتكون من المصدر الأساسي الذي يحتوي على المعلومات

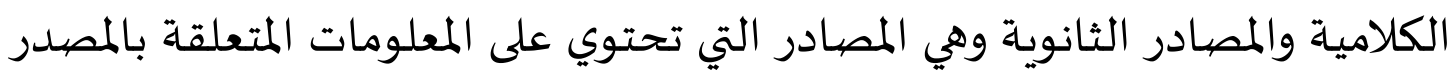
الأساسي ككتب التفاسير والأحاديث النبوية، والكتب اللغوية، والكتب الأخرى. وطريقة جمع البيانات هي التسجيل والملاحظة من المصدر الأساسي وتحليل البيانات عن طريقة تحليل علم الكلام.

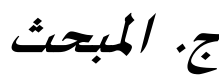

\section{Pantheisme معنى وحدة الوجود}

$$
\text { المفهوم اللغوي للفظ وحدة الوجود:- }
$$

الوحدة في اللغة من التوحيد، يقال رجل متوحد: أي لا يخالط الناس، وتوحدود لوحد

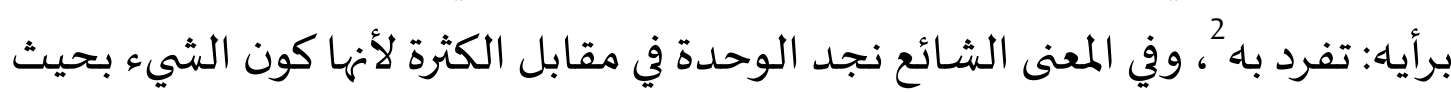
لا ينقسم، والكثرة بحيث ينقسم 3

الوجود مصدر فعله وجد يجد، ومعناه يقابل معنى العدم، ورد في المعجم بهم بهم

$$
\text { الوجيز الوجود: ضد العدم، وهو ذهني وخارجي } 4
$$

${ }^{2}$ Ibn Manzur Al-Ifrīqī, Lisan Al-Arab, Juz 3, (Cairo: Darul Ma'arif, 1970), h. 888.

${ }^{3}$ Jamīl Șalībā, Al-Mu’jam Al-Falsafi, Juz 2 (Beirut: Dar Al-Kitab Al-Lubnani, 1971), h. 567.

${ }^{4}$ Academy of the Arabic Language, Al-Mu'jam Al-Wajiz (Cairo: Ministry of Education, 1994), h. 661. 


\section{المفهوم الصيوفي لكلمة وحدة الوجود:-}

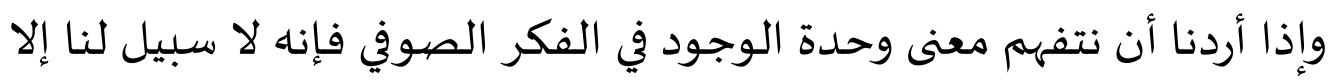

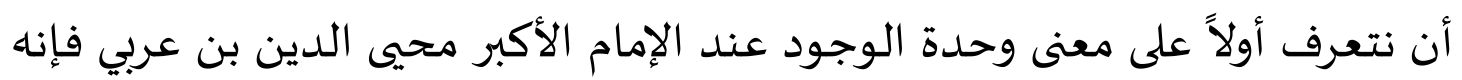

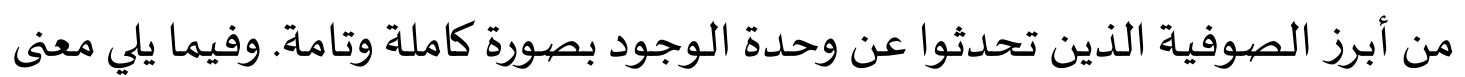

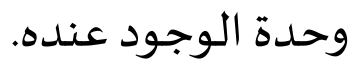

$$
\text { حقيقة وحدة الوجود عند ابن عربي:- }
$$

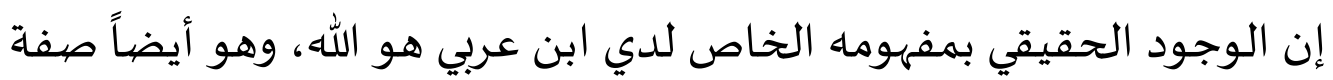

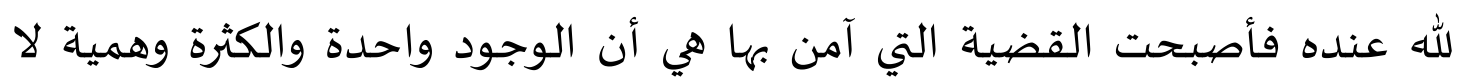

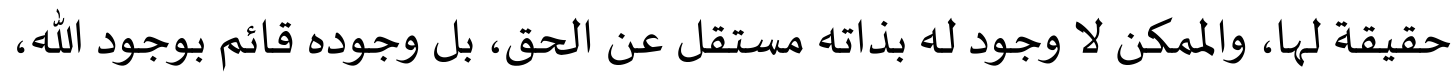

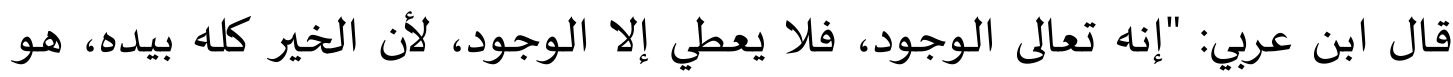

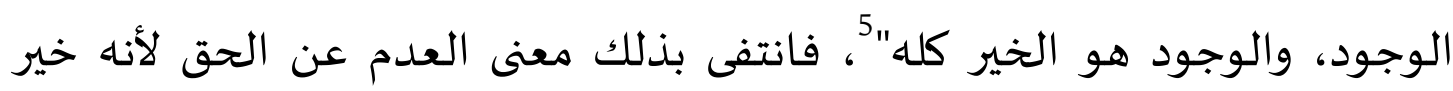

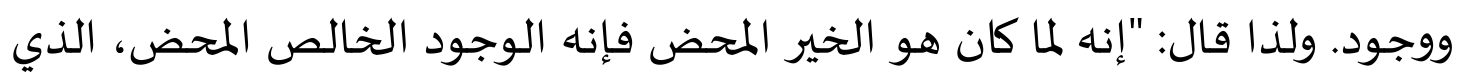

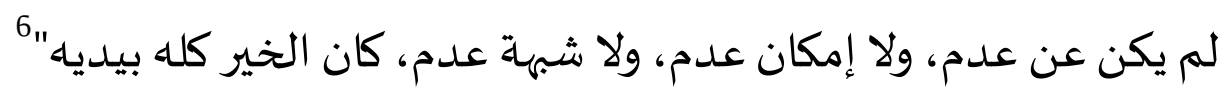

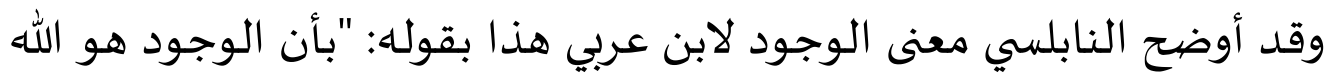

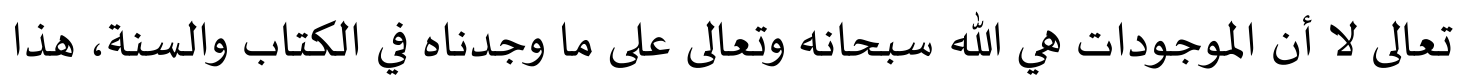

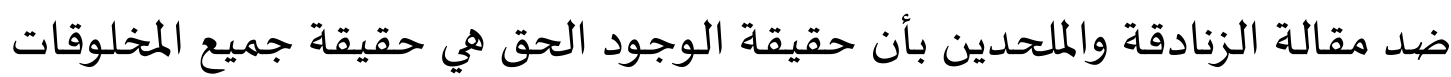

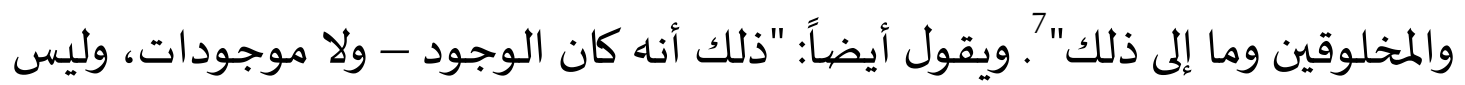

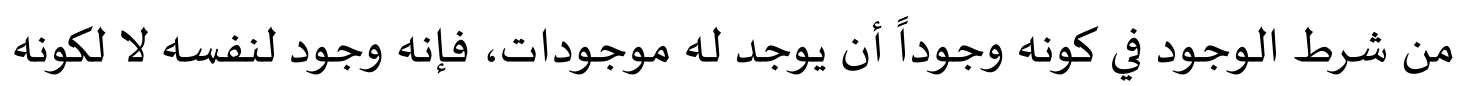

\footnotetext{
${ }^{5}$ Muhyi al-Din Ibn Arabi, Al-Futuhat Al-Makkiyah, Juz 4 (Cairo: Mathba'ah Bolaq), h. 385.
}

${ }^{6}$ Muhyi al-Din Ibn Arabi, Al-Futuhat Al-Makkiyah, Juz 36 ed. by Utsman Yahya (Cairo: AlHaeah Al-Misriyah Al-'Ammah Lil Kitab, 1985), h. 262-263.

${ }^{7}$ Abd al-Ghani Al-Nabulsi, Kitab Al-Wujud Wa Khitab Al-Syuhud Fi Al-Tasawwuf Wa AlSufiyyin (Damascus: Makhtut al-Ẓāhirīyyah), h. 215. 
وجوداً للموجودات، وجميع ماعدا الوجود مفتقر إلى الوجود" . ويزيد أبو العلا عفيفي

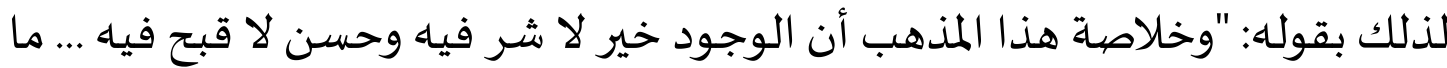

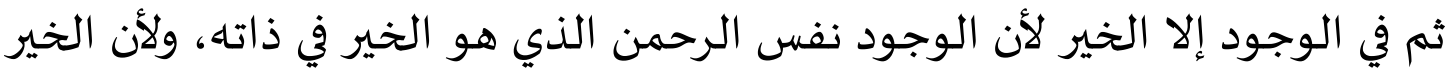

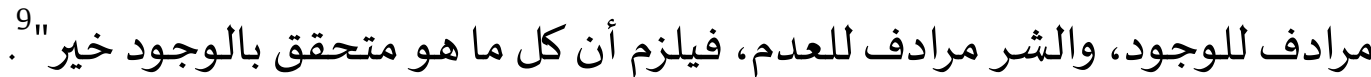

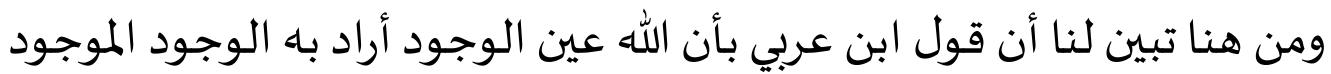

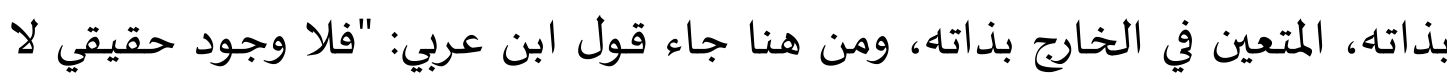

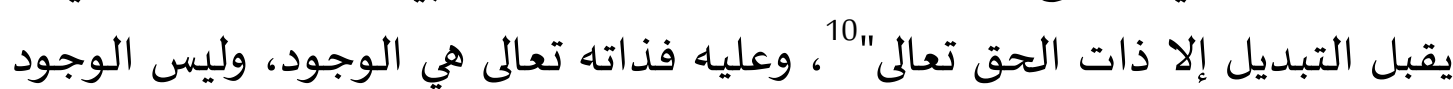

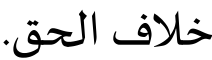

ولهذا فقد حصر ابن عربي وجود الموجودات في قبضة الحق لإضافة الوجود إليها، وظهورها باه، ونفى قدرتها على الوجود بمعزل عن الله لاستحالة ذلك: "فإن كل ما سوى الله لا يمكنه الخروج عن قبضة الحق، فهو موجدهم بل بله [هو سبحانه] وجودهم، ومنه استفادوا الوجود وليس الوجود خلاف الحق، ولا خارجاً عنه يعطيهم

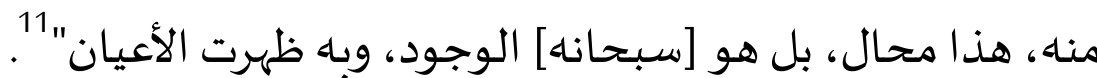
هكذا يضيف ابن عربي الحق بالوجود على حين ينفي ذلك عن الموجودات لافتقارها إلياء تعالى، وانعدام كل شيء معه، فالله هو الموصوف بالوجود على الحقيقة

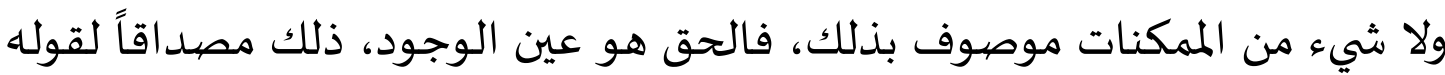

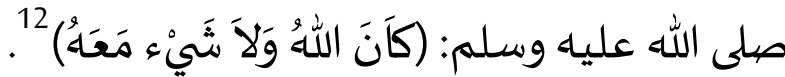

${ }^{8}$ Al-Nabulsi Kitab Al-Wujud Wa Khitab Al-Syuhud Fi Al-Tasawwuf Wa Al-Sufiyyin, h. 215.

${ }^{9}$ Abu Al-Ula Afifi, Al-Muqaddimah Wa Al-Ta'liqat A'la Fusus Al-Hikam (Beirut: Dar alKitab al-Arabi), h. 339.

${ }^{10}$ Muhammad bin Abd al-Rasul Al-Barazanji, Al-Janib Al-Ghaibi Fi Hilli Musykilat Ibn Arabi (Damascus: Maktabah Riyadh al-Malih), h. 385.

${ }^{11}$ Ibn Arabi, Al-Futuhat Al-Makkiyah, Juz 36, h. 167.

${ }^{12}$ Abu Abdillah Al-Bukhari, Al-Jami' Al-Sahih, Juz 4 (Beirut: Dar Tauq al-Najah, 2001), h. 105. 
وهكذا فإن هذه القضية لعبت الدور الأكبر في تفصيلات مذهب وحدة الوجود عنده، إذ بنى عليها تصوفه القائم على الذوق والوجدان، بالإضافة إلى إعمال العقل والفكر فيها.

وانطلاقاً من مفهومه للوجود هذا، فمعنى وحدة الوجود عنده إنما هو أن

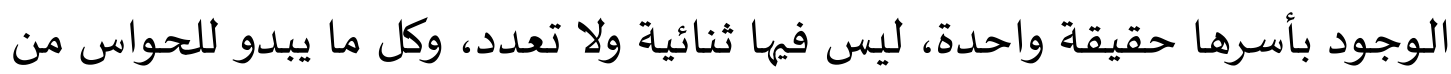

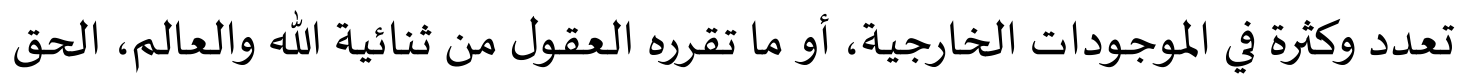

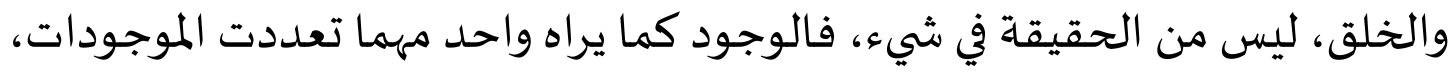

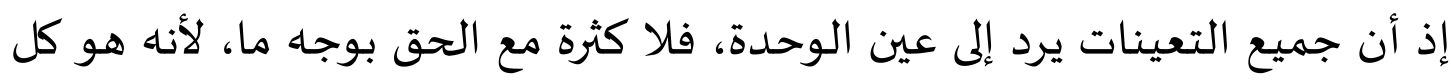

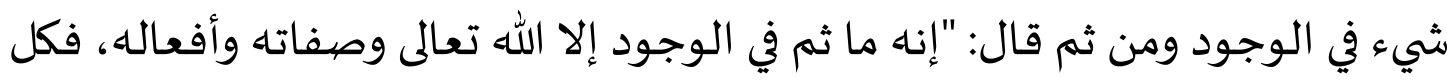

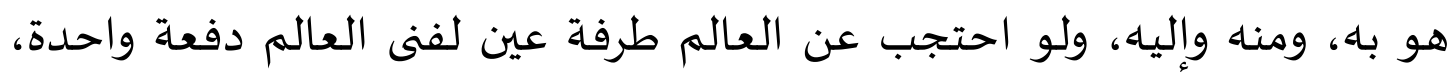

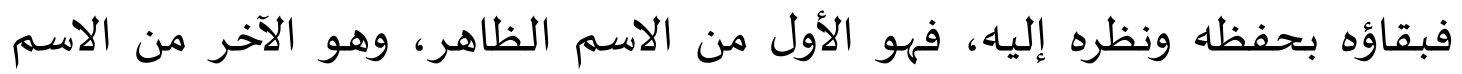

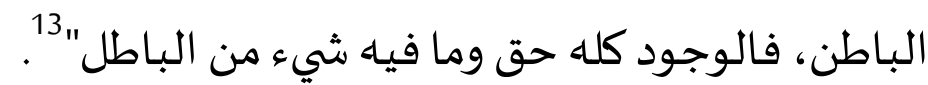

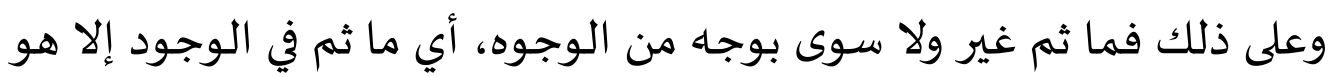

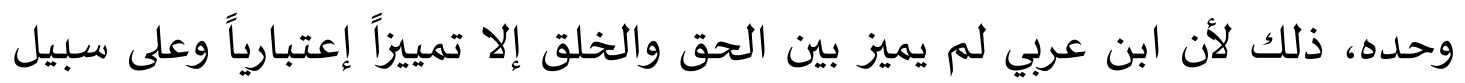
الفهم والتوضيح لأفكاره. وهذا معنى وحدة الوجود عند ابن عربي، فما ثم إلا حق في كل وجود، وما ثم موجود إلا الله تعالى على كل وجاه، علم ذلك من علماه، وجهل ذلك الك من جهلها.

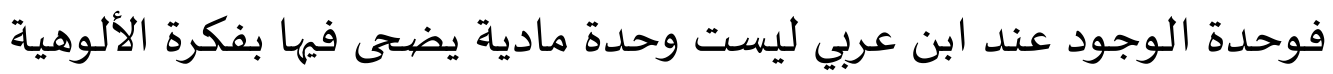

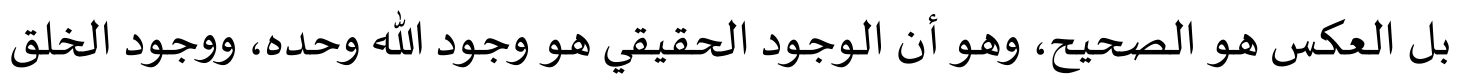

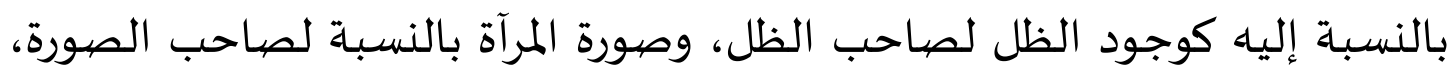
فالخلق شبح زائل للوجود الحقيقي ل1.

${ }^{13}$ Ibn Arabi, Al-Futuhat Al-Makkiyah, juz 3, h. 317.

${ }^{14}$ Abu Al-Ula Afifi, 'Majalah Turats Al-Insaniyah', Turats Al-Insaniyah, 2.1 (1962), h. 167. 
وإنها أيضاً ليست وحدة وجود فلسفية، فإنه على رغم استخدامه لبعض كأن

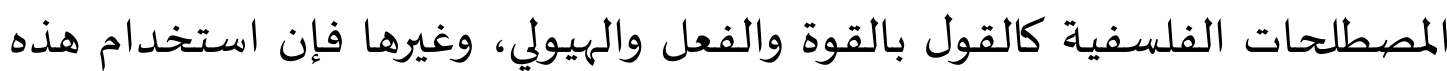

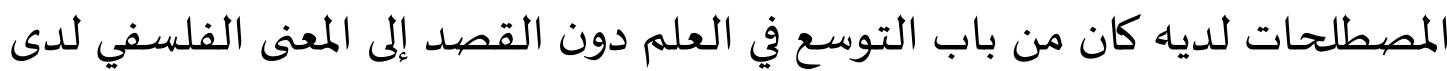
الفلاسفة، وكذلك امتلاكه للناحية العقلية النقدية التي يتصف بها الفيلسوف كانت دلالة على تصوف صاح واع لدياء لا شطح فيه ولا خروج عن حدود العقيدة والشرع مما يؤكد تصوفه الخالص عن كل شائبة مادية وعدم صبغة بالصبغة الفلسفية،

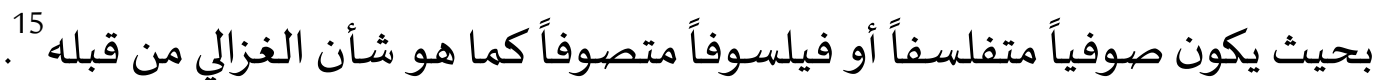

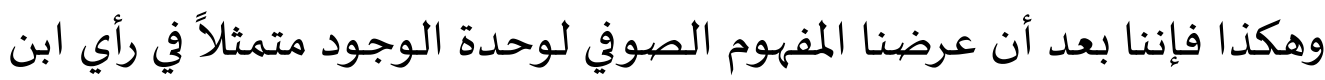
عربي عنها باعتباره أبرز الصوفيين القائلين بوحدة الوجود على وجاء كامل وتام، وانتهينا

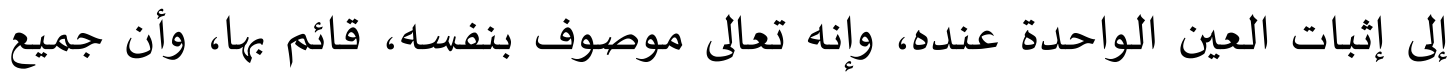

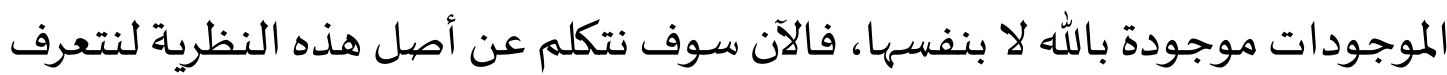

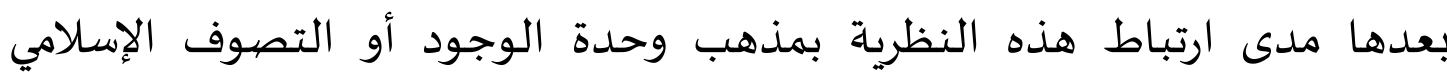
الفلسفي.

\section{الأصل الديني لهذه النظرية}

وقد اعتمدت أصحاب مذهب وحدة الوجود في دعم عقيدتهم الوجودية على لهـي مصدر قرآني ونبوي، والنبوي يشتمل على الأحاديث القدسية والأحاديث الشريفة الشئ.

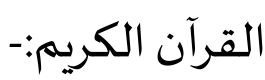

أقام ابن عربي تصوفه على الذوق والقلب مستمداً مصادره من الأصول التي تستمد منها أحكام الشريعة وفي ذلك يقول شعراً:

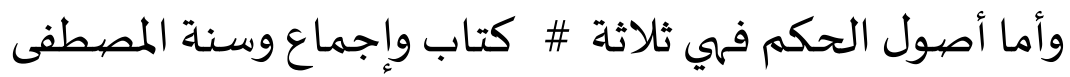

${ }^{15}$ Suhailah Abd al-Bai'ts, Nazariyah Wahda Al-Wujud Baina Ibn Arabi Wa Al-Jaili (Beirut: Maktabah Khaz'al, 2002), h. 261. 


\section{ورابعها منا قياس محقـق وفياه خلاف بينهم مر وانتفى 16}

فمن القرآن الكريم استلهم ابن عربي عقيدتاه في التوحيد، وعول على على الآيات

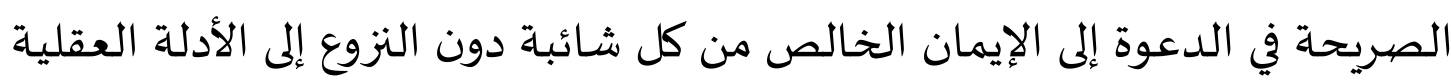
وحدها فقال: "ولا يخفى أن الشخص إذا كان مؤمناً بالقرآن قطعاً بأنه كلام الله تعالى.

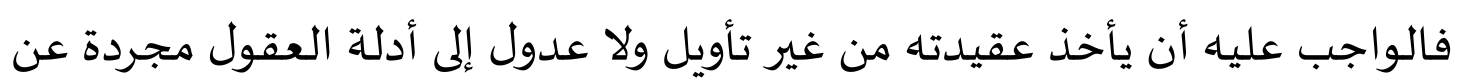

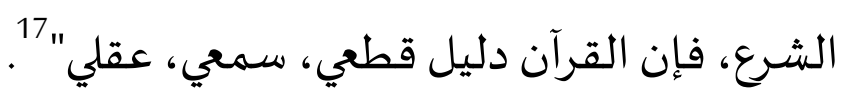

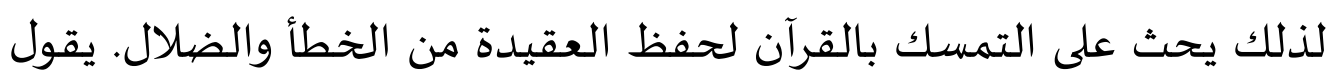

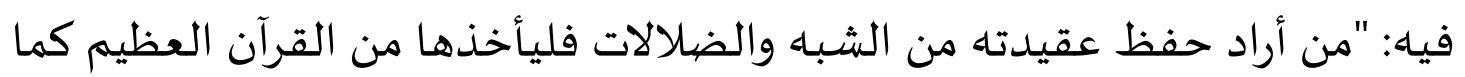

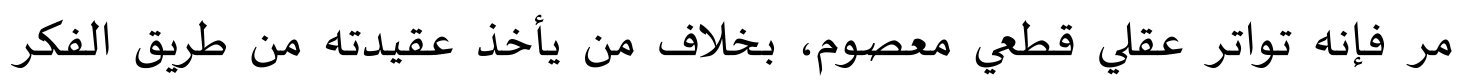

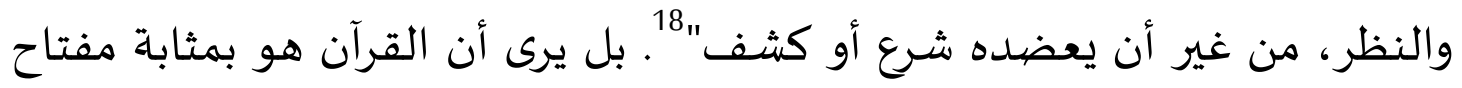

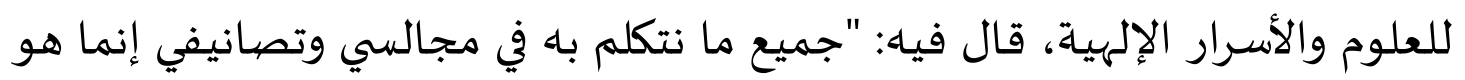

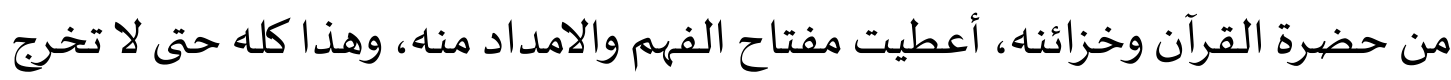

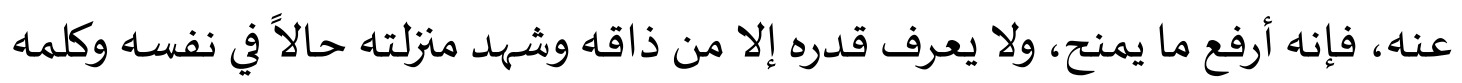

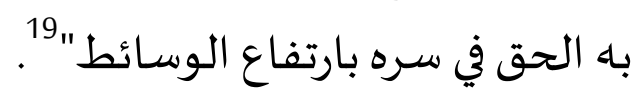

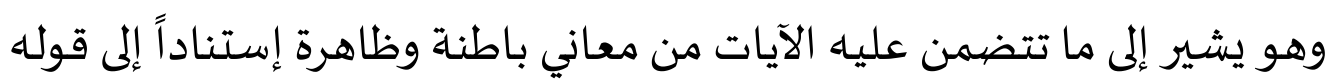

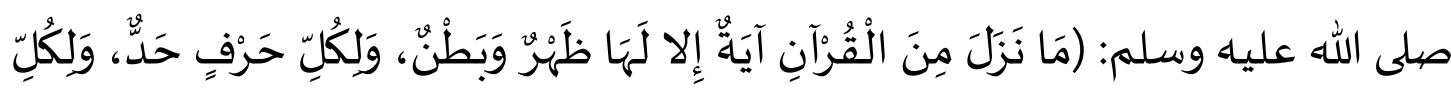

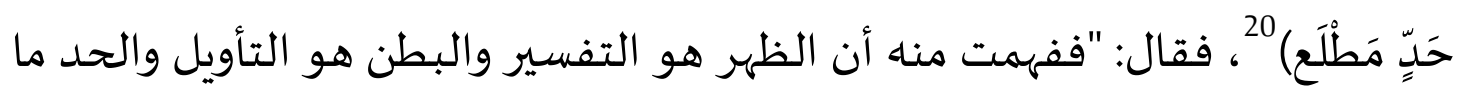

${ }^{16}$ Abd al-Aziz Sayyid al-Ahl, Muhyi Al-Din Ibn Arabi Min Syi'rih (Beirut: Dar al-I'lmi Lilmalayin, 1970), h. 134.

17 Abd al-Wahab Al-Sha'rani, Al-Yawaqit Wa Al-Jawahir, Juz 1 (Cairo: Maktabah Isa alBabi al-Halabi, 1959), h. 22.

${ }^{18}$ Al-Sha'rani, Al-Yawaqit Wa Al-Jawahir, Juz 1, h. 23.

${ }^{19}$ Ibn Arabi, Al-Futuhat Al-Makkiyah, juz 3, h. 340.

${ }^{20}$ Abu Muhammad Al-Bagawi, Syarh Al-Sunnah, Juz 1, ed. by Syuaib Al-Arnauth and Zuhair Al-Shawish (Beirut: Al-Maktab al-Islami, 1983), h. 262. 
ينتهي إليه الفهوم من معنى الكلام، والمطلح ما يصعد إليه منه فيطلح على شهود الملك

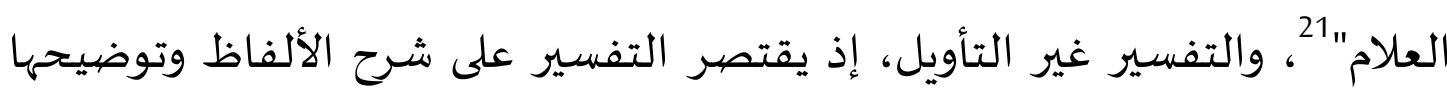

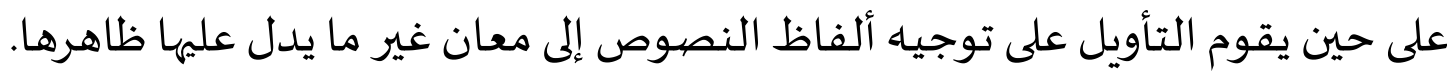
قال الجرجاني: "التأويل صرف اللفظ عن معناه الظاهر إلى معنى يحتمله إذا كان

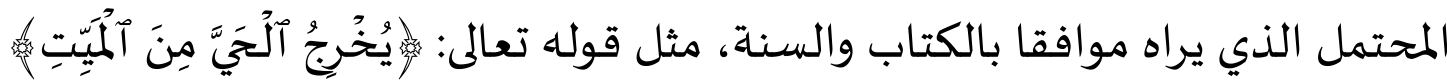

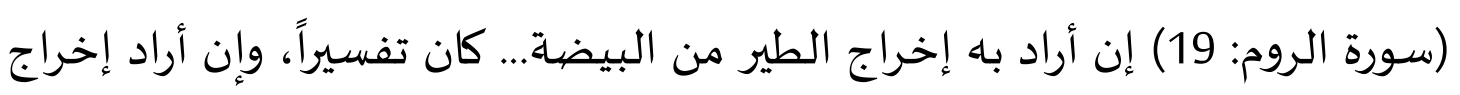
المؤمن من الكافر أو العالم من الجاهل كان تأويلاًا ل22.

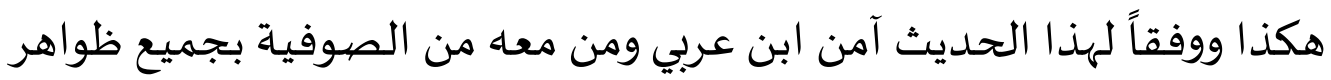

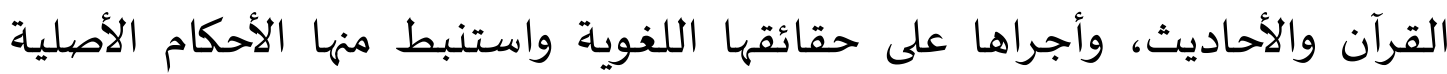

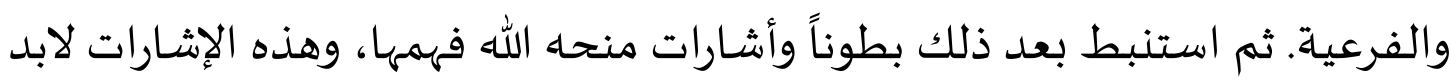

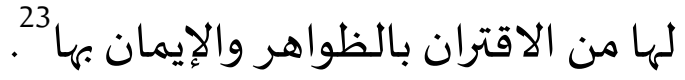

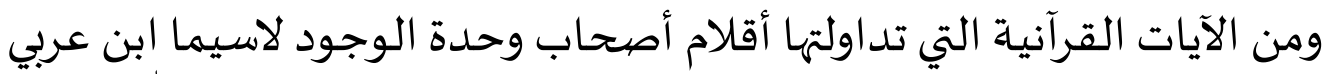

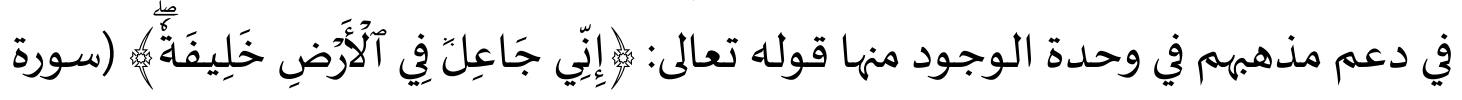

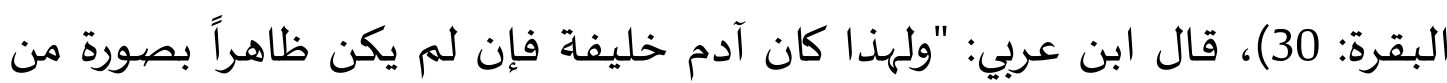
استخلف فيما استخلفه فياه فماهو خليفة، وإن لم يكن فياه جميع ما تطلبه الرعايا التي استخلف عليها لأن إستنادها إليه فلا بد أن يقوم بجميع ماتحتاج إنهاجيه إليه، وإلا

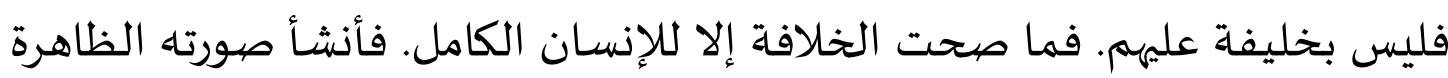
من حقائق العالم وصوره وأنشأ صهورته الباطنة على صورته تعالى، ولذلك قالك الكال فيهاء:

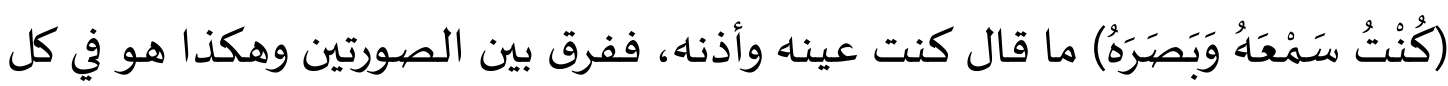

${ }^{21}$ Muhyi al-Din Ibn Arabi, Tafsir Al-Qur'an Al-Karim, Juz 1, (Beirut: Dar al-Yaqzah alArabiyah, 1968), h. 4.

${ }^{22}$ Ali bin Muhammad Al-Jurjany, Kitab al-Ta'riifaat (Amman: Dar al-Nafais, 2003), h. 112.

${ }^{23}$ Al-Barazanji, Al-Janib Al-Ghaibi Fi Hilli Musykilat Ibn Arabi, h. 30. 
موجود من العالم بقدر ما تطلباه حقيقة ذلك الموجود، ولكن ليس لأحد مجموع ما

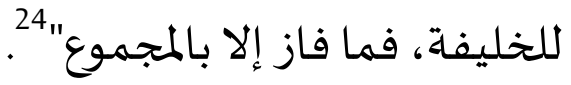

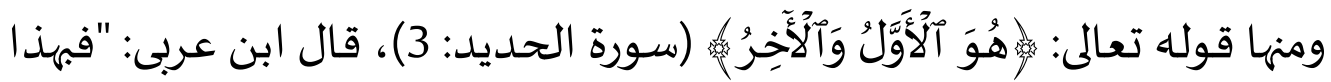

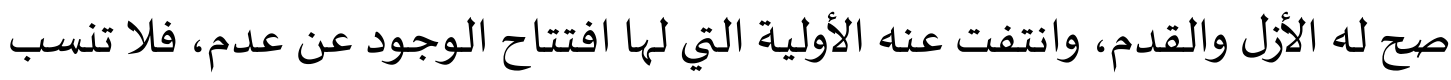

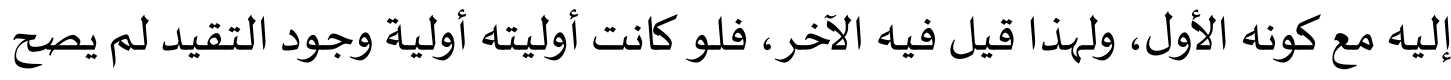

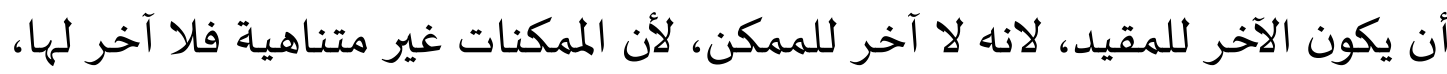

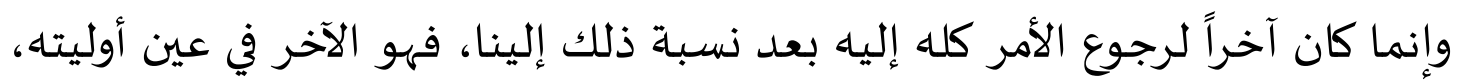
والأول في عين آخريته"

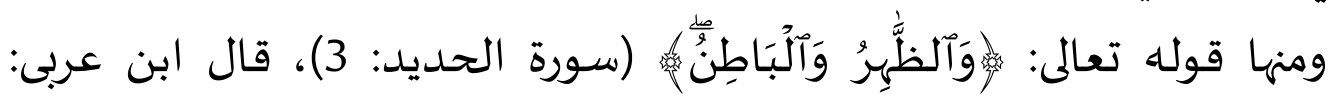
"فالحق هو الظاهر في كل مفهوم وهو الباطن عن كل فهم إلا عن فهم من قال أن العالم صورته وهويته، وهو الاسم الظاهر كما أنه بالمعنى روح ما ظهر، فهو هوه البه الباطن. فنسبته لما ظهر من صور العالم نسبة الروح المدبر للصيورة"

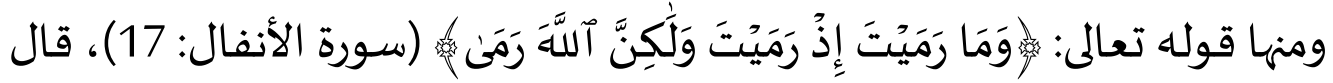

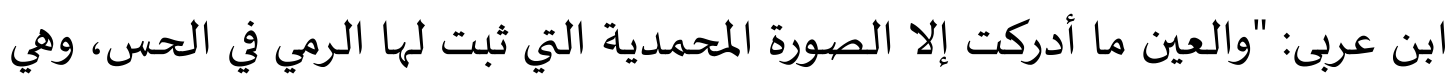

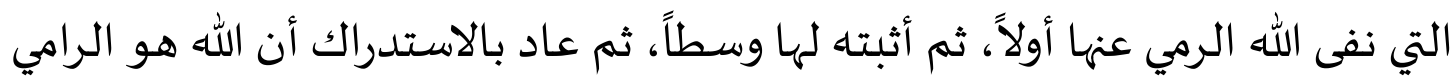

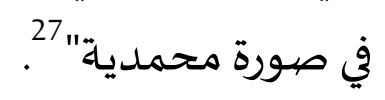

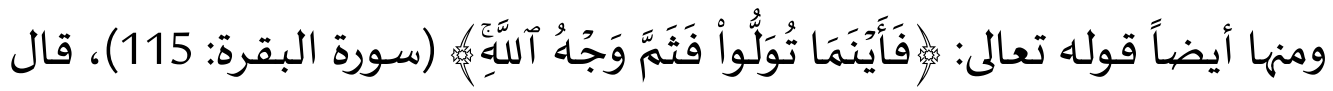
ابن عربى:"ويقصد من ذلك أنه أي جهاة تتوجهوا في الظاهر والباطن فثم وجها الله، أي ذات الله المتجلية في صفاته، ولله الإشراق على قلوبكم بالظهور بها والتجلي لها بصنية

${ }^{24}$ Muhyi al-Din Ibn Arabi, Fusus Al-Hikam, ed. by Abu Al-Ula Afifi (Beirut: Dar al-Kitab al-Arabi), h. 55.

\footnotetext{
${ }^{25}$ Ibn Arabi, Fusus Al-Hikam, h. 54.

${ }^{26}$ Ibn Arabi, Fusus Al-Hikam, h. 68.

${ }^{27}$ Ibn Arabi, Fusus Al-Hikam, h. 185.
} 
جماله حالة شهودكم وفنائكم... فأي جهة تتوجهوا حينئذ فثم وجاء الله، لم يكن شيء إلا باه وحده، عليم بكل العلوم والمعلومات"

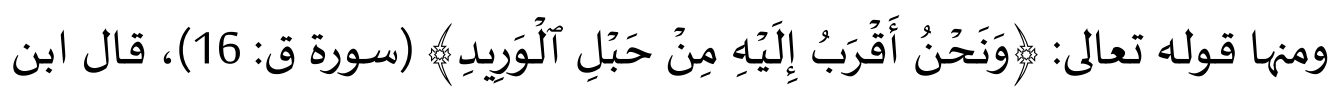

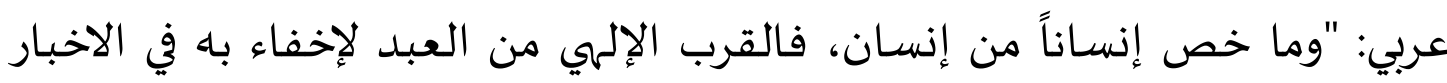

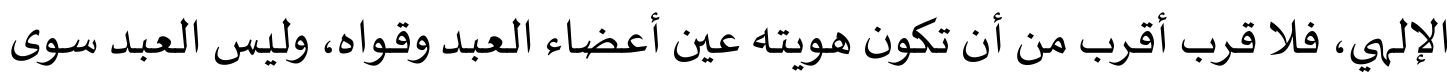

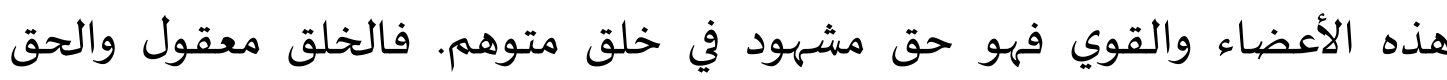

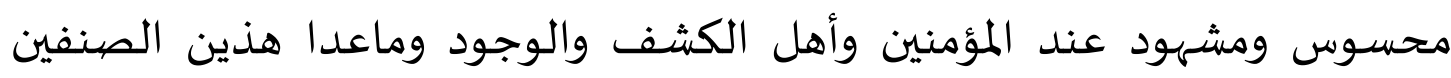

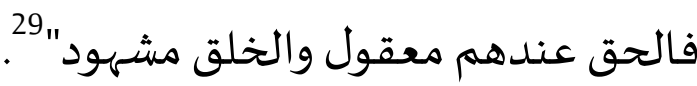

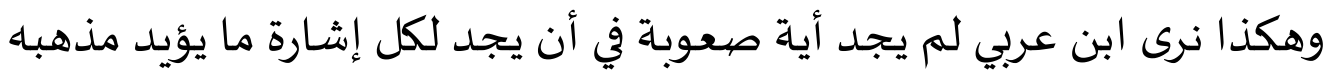

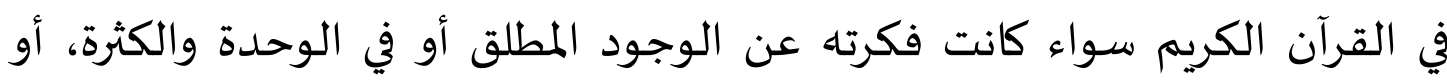

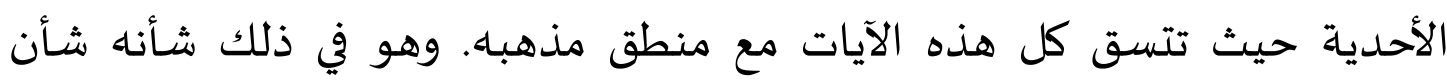

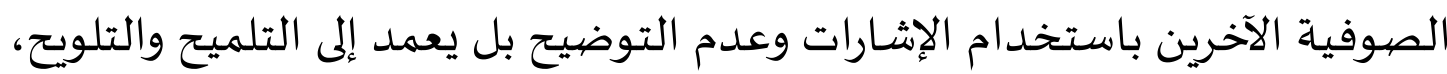

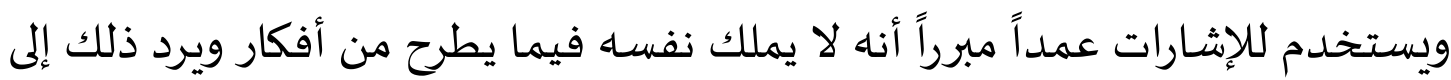
أن نمط كتبه لا يخضع للمنطق والنظام والترابط الفكري بل هي إلقاء رباني يلقياه في

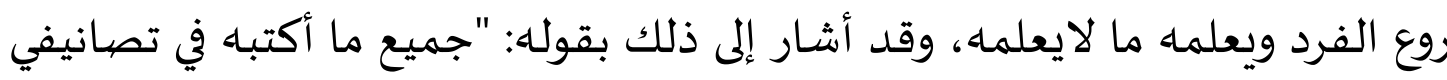
ليس هو عن فكر ولا روية، إنما هو عن نفث في روعي من ملك الإلهام"

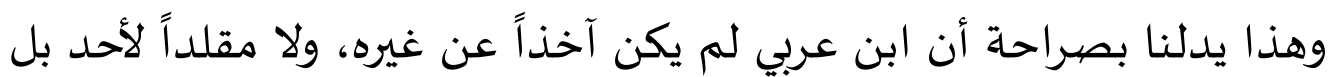
إنما علماه منة وهبة من الله يمنحها لخاصتها.

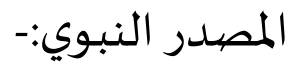

\footnotetext{
${ }^{28}$ Ibn Arabi, Tafsir Al-Qur'an Al-Karim, Juz 1, h. 80.

${ }^{29}$ Ibn Arabi, Fusus Al-Hikam, h. 108.

${ }^{30}$ Al-Sha'rani, Al-Yawaqit Wa Al-Jawahir, Juz 1, h. 24.
} 
وقد ذكرنا سابقاً بأن ابن عربي التزم في تصهوفه بما جاء في الكتاب والسنة، ويتضح ذلك أيضاً في قوله: "إعلم أني لم أقرر بحمد الله تعالى في كتابي هذا ولان الها في غيره

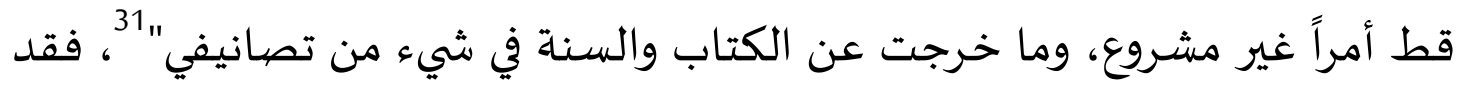

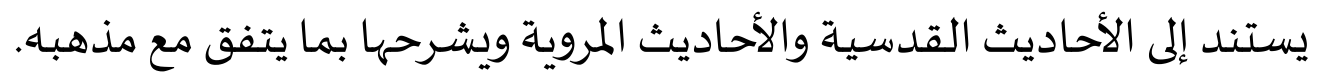

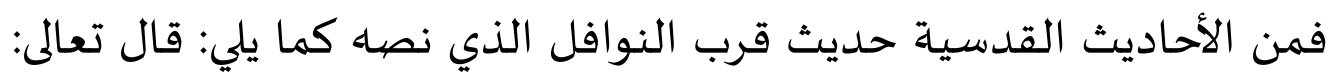

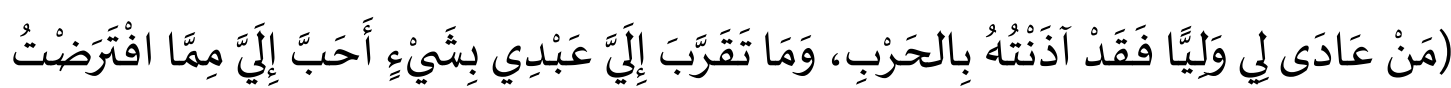

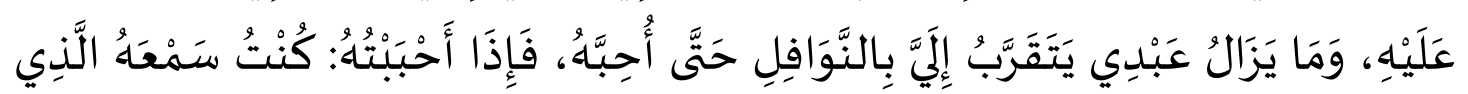

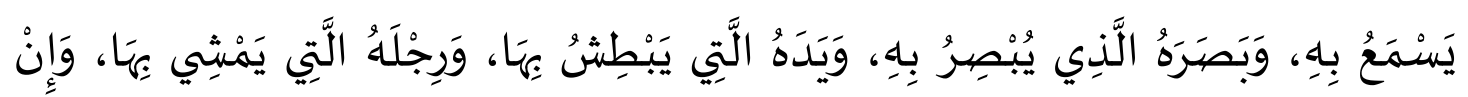

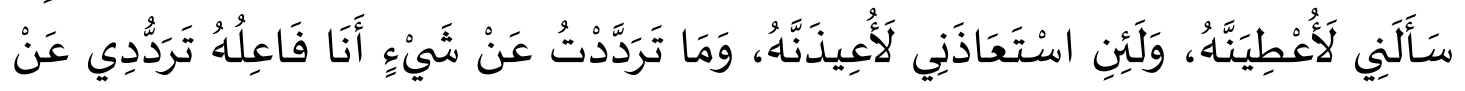

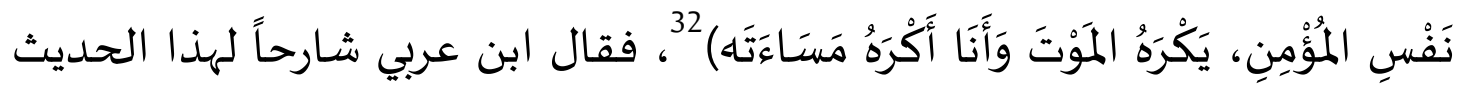

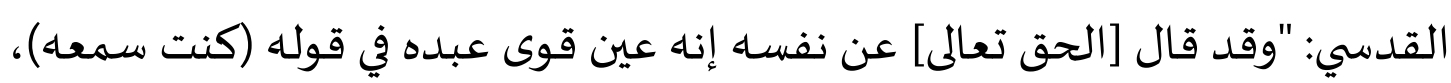

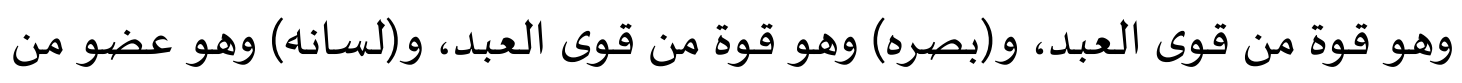

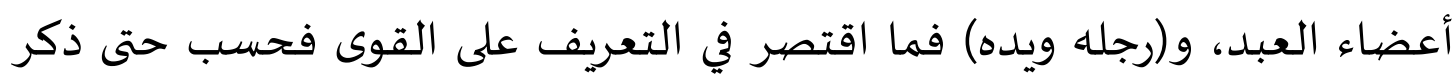

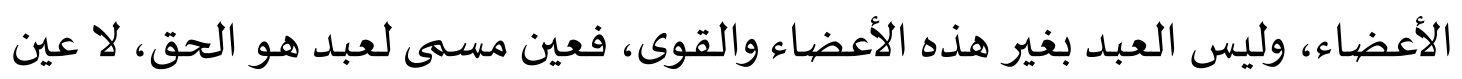

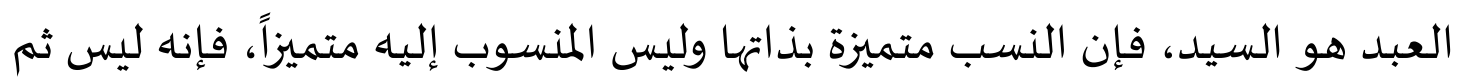

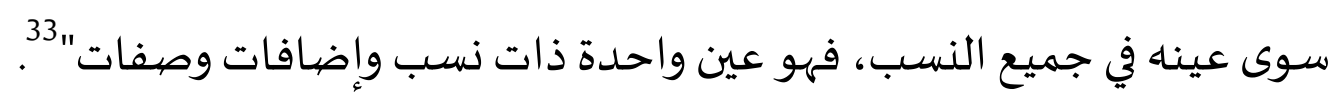

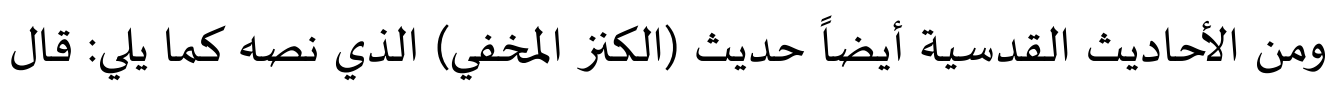

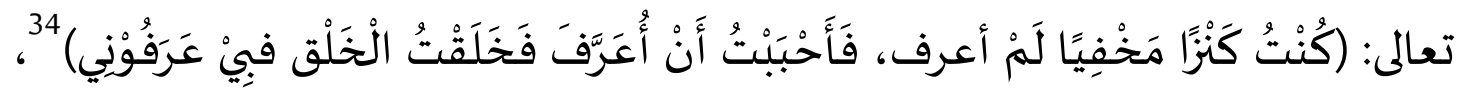
وهذا الحديث يثير في الذهن المفهومات والقين اعرفيم التالية:

\footnotetext{
${ }^{31}$ Al-Sha'rani, Al-Yawaqit Wa Al-Jawahir, Juz 1, h. 24.

${ }^{32}$ Al-Bukhari, Al-Jami’ Al-Sahih, No. 6137 Juz 8, h. 105.

${ }^{33}$ Ibn Arabi, Al-Futuhat Al-Makkiyah, Al-Safar 1, h. 189.

34 Ismail bin Muhammad Al-A'jluni, Kashf Al-Khafa Wa Muzil Al-Ilbas, Juz 2, (Cairo: Maktabah al-Maqdisi, 1932), h. 132.
} 


$$
\text { أ - الوجود في قوله تعالى (كنت) }
$$

ب - المحبة بما هي دافع ذاتي إلى الخلق في قوله تعالى (فأحببته)

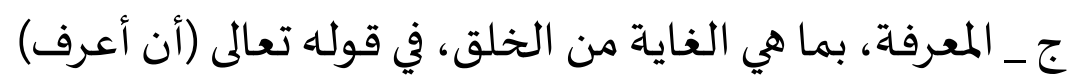

د - الخلق، بما هو وسيلة لمعرفة الخلق للحق تعالى في قوله (فخلقت الخلق)

هـ - مقام معرفة الحق بالخلق ومقام معرفة الخلق بالحق في قوله (فبي عرفوني)

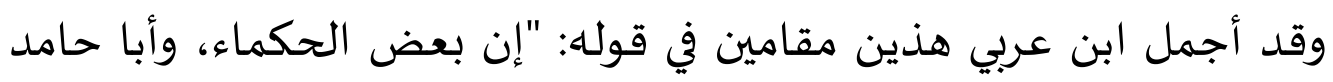

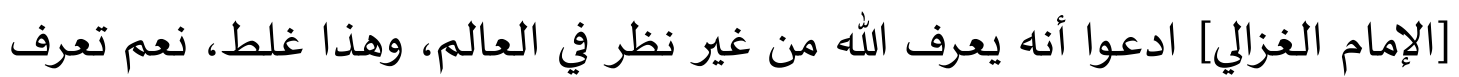
ذات قديمة أولية لا يعرف أهها إله حتى يعرف المألوه، فهو (المألوه) دليل على (الإله)،

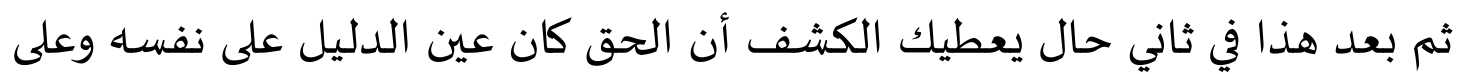

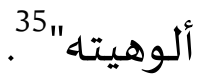

وفي المحبة ودورها في فعل الخلق يقول ابن عربى: "فلولا هذه المحبة ما ظهر

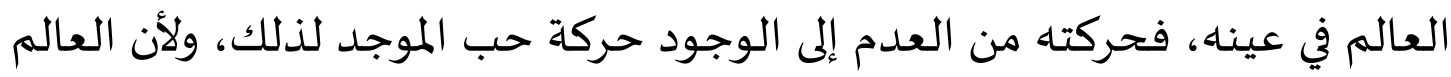

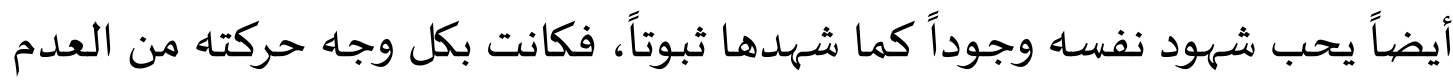
الثبوتي إلى الوجود حركة حب من جانب الحق وجانبه [من جانب العالم]. فإن الكمال

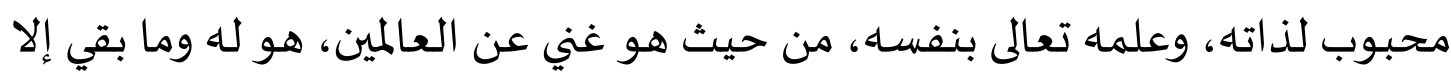

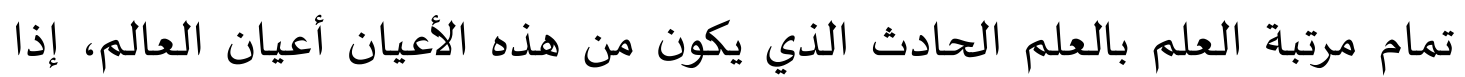

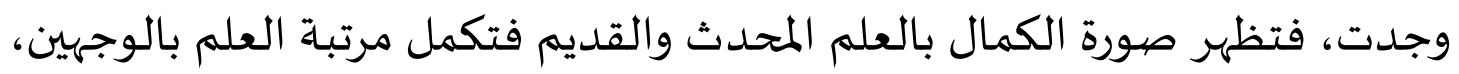

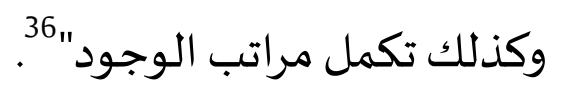

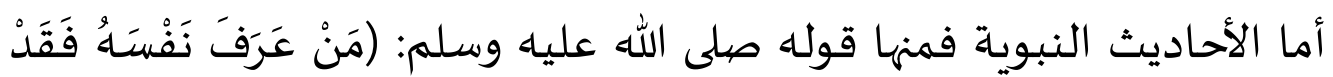

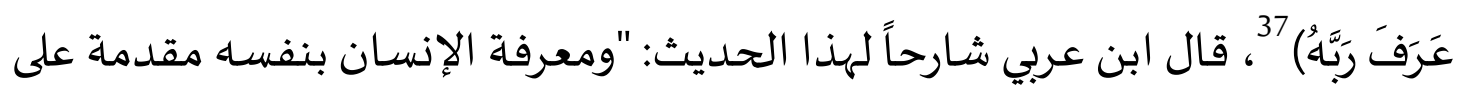

${ }^{35}$ Ibn Arabi, Fusus Al-Hikam, h. 18.

${ }^{36}$ Ibn Arabi, Fusus Al-Hikam, h. 203-204.

${ }^{37}$ Abu Nuaim Al-Isfahani, Hilyat Al-Awliya Wa Tabaqat Al-Ashifa, Juz 10, (Cairo: Maktabh al-Sa'adah, 1974), h. 208. 
معرفته برباه، فإن معرفته برباه نتيجة عن معرفتاه بنفسـاه، لذلك قال عليه السلام:

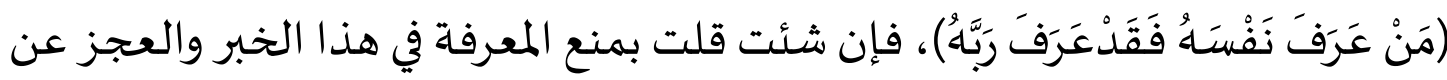

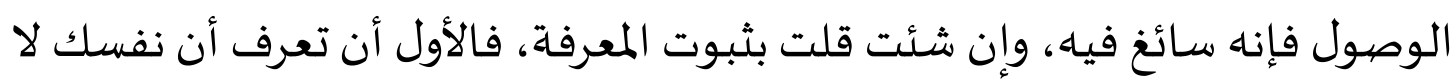

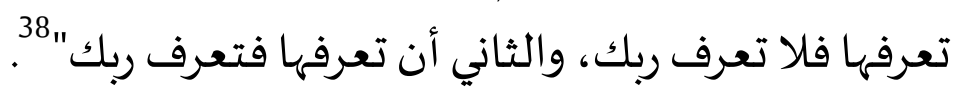

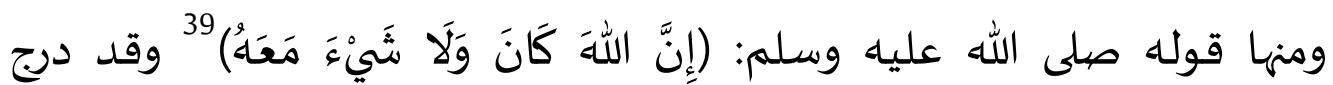
الصوفية على تذييل هذا الحديث بقولهم: "وهو الآن على ما عليه كان" بذلك أن العالم لا وجود لله على الحقيقة وإنما الوجود هو الله تعالى وحده.

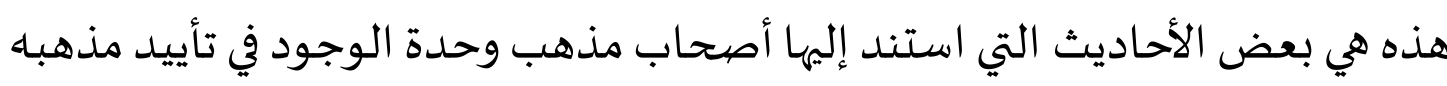
في وحدة الوجود.

وجملة القول نرى أن ابن عربي ومدرسته بعده قد جعل القرآن والحديث

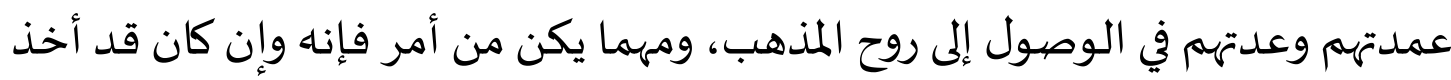

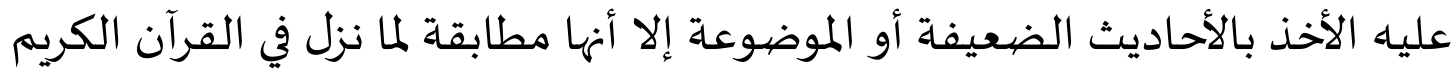

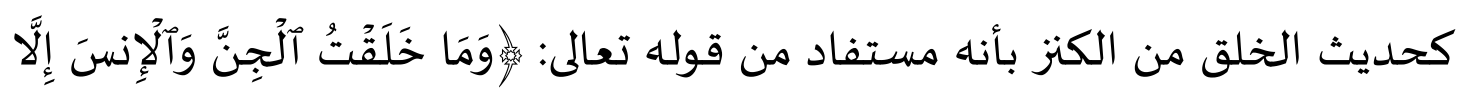

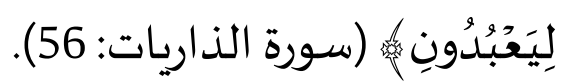

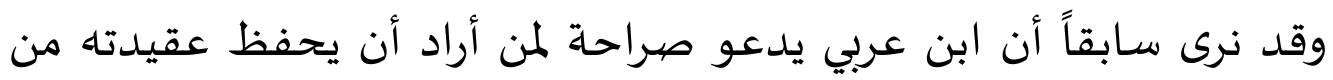

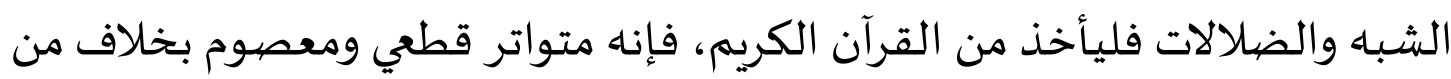

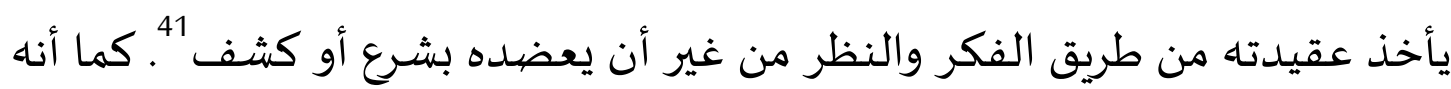

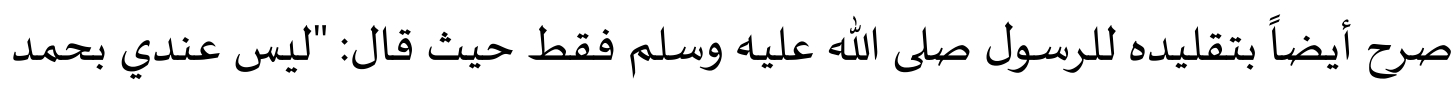

\footnotetext{
${ }^{38}$ Ibn Arabi, Fusus Al-Hikam, h. 215.

${ }^{39}$ Al-Bukhari, Al-Jami' Al-Sahih, Juz 4, h. 105.

${ }^{40}$ Ibn Arabi, Al-Futuhat Al-Makkiyah, Al-Safar 1, h. 189.

${ }^{41}$ Al-Sha'rani, Al-Yawaqit Wa Al-Jawahir, Juz 1, h.23.
} 
الله تقليد لأحد غير رسول الله صلى الله عليه وسلم، فعلومنا كلها محفوظة من

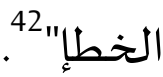

وهذا يؤكد القول بأنه لم يحد عن الكتاب والسنة في كل مصنفات مما يثبت

صحاة عقيدتاه وصدق مذهباه ويستوجب عدم الطعن فيها والتنكر لها.

$$
\text { المطلب الثالث: موقف العلماء منها }
$$

اختلف العلماء في تقدير مذهب وحدة الوجود اختلافاً شديداً، حتى انقسموا

إلى فريقين متعارضين: فريق يرى هذا المذهب يتمشى مع روح العقيدة الصحيحة

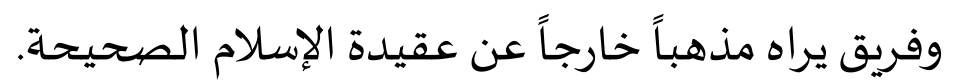

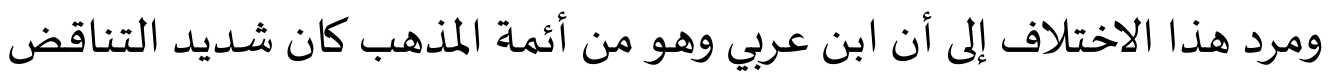

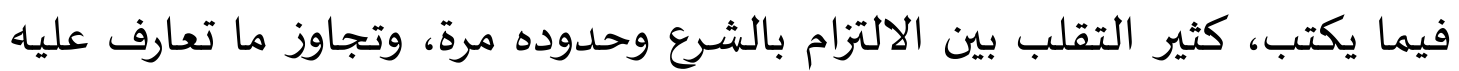

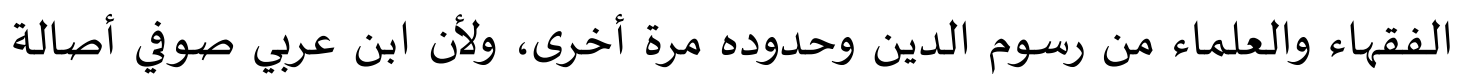

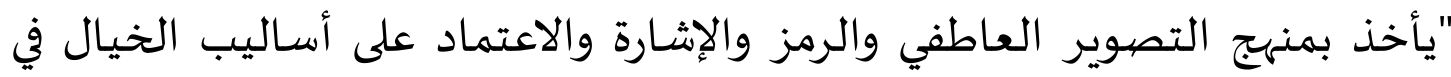

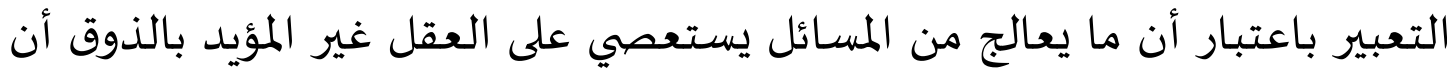
يدركها، ويستعصي على غير اللغة الرمزية أن تفصح عن أسرارها"

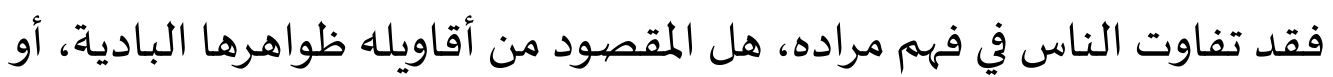

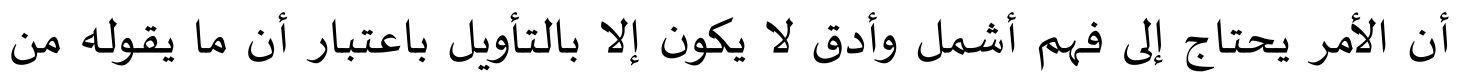

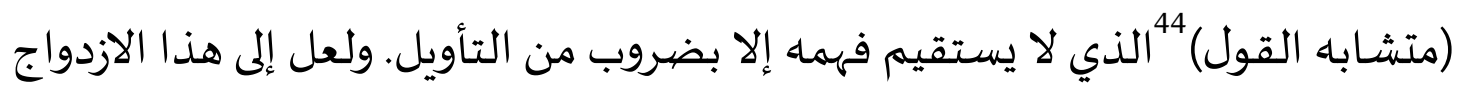

${ }^{42}$ Al-Sha'rani, Al-Yawaqit Wa Al-Jawahir, Juz 1, h.24.

${ }^{43}$ Afifi, Al-Muqaddimah Wa Al-Ta'liqat A'la Fusus Al-Hikam, h. 9.

${ }^{44}$ Ibn Hajar Al-A’skalani, Lisan Al-Mizan, Juz 5 (Beirut: Dar al-Bashair al-Islamiyah, 2002), h. 310 . 
في لغة التعبير أشار المؤرخون عندما وصفوه بأنه (ظاهري المذهب) في العبارات، (باطني النظر) في الاعتقادات ل45.

بالإضافة إلى ما سبق أن ابن عربي قد أذاع مذهبات في وحدة الوجات الودود مشتتاً بين

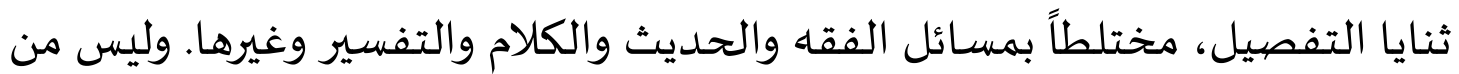
شك في أنه تعمد هذا التشتيت لعناصر مذهبها إمعاناً في إخفاء حقيقته الكاملة وضناً التهاً

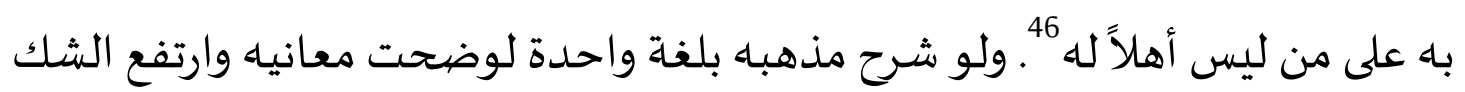

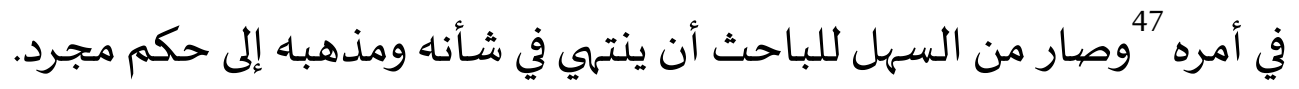

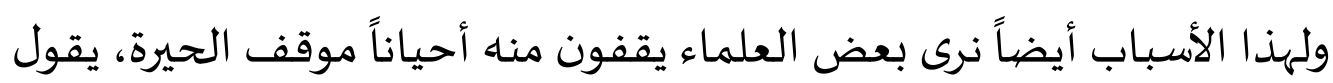

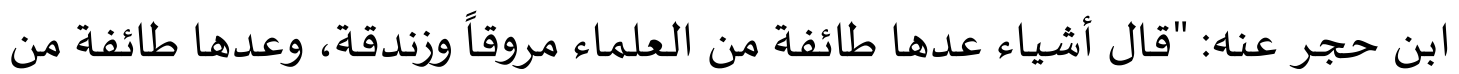

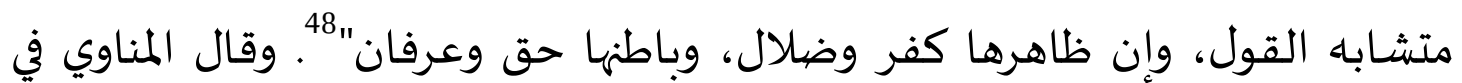

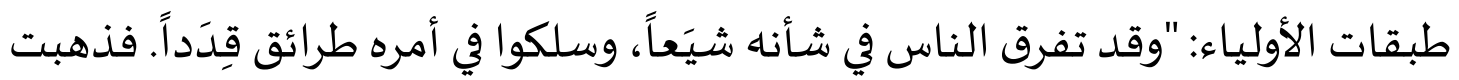
طائفة إلى أنه زنديق لا صديق، وقال قوم إنه واسطة عقد الأولياء ورئيس الأصفياء،

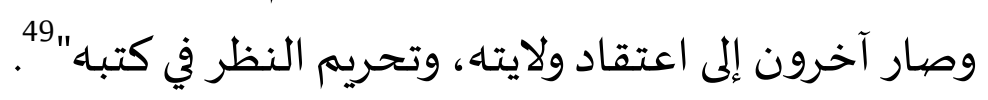

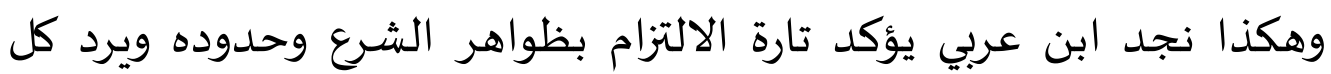

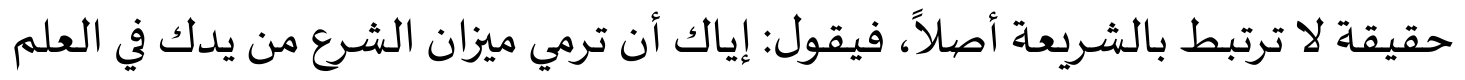
الرسمي، بل بادر إلى العمل بكل ما حكم باه وإن فهمت منه خلاف ما يفهماه الناس، مما يحول بينك وبين إمضاء ظاهر الحكم فلا تقول عليه، فإنها مكر إلهي بصورة علم إلهي 1995), h. 362.

${ }^{45}$ Ahmad Muhammad Al-Maqqari, Nafh Al-Tib, Juz 2, (Beirut: Darul Kutubil I'lmiyah,

${ }^{46}$ Abu Al-Ula Afifi, Ibn Arabi Fi Dirasati-Al-Kitab Al-Tizkari (Cairo: Dar al-Kitab al-Arabi, 1969), h. 16.

${ }^{47}$ Afifi, Ibn Arabi Fi Dirasati-Al-Kitab Al-Tizkari, h. 13.

${ }^{48}$ Al-A'skalani, Lisan Al-Mizan, Juz 5, h. 310.

${ }^{49}$ Ibnul I'mad Al-Hanbaly, Shadzarat Ad Dzahab Fi Akhbar Man Dzahab, Juz 5, (Beirut: Darul Kutubil I'lmiyah, 1990), h. 192. 
من حيث لا تشعر، ثم قال: "واعلم أن تقديم الكشف على النص ليس بشئ عندنا،

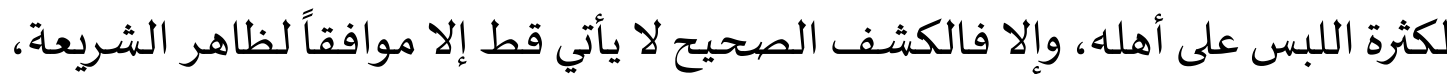

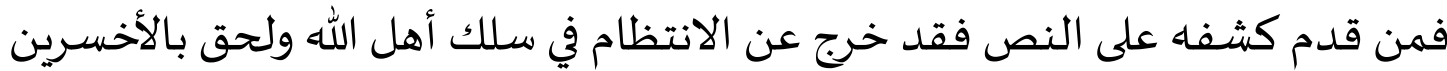

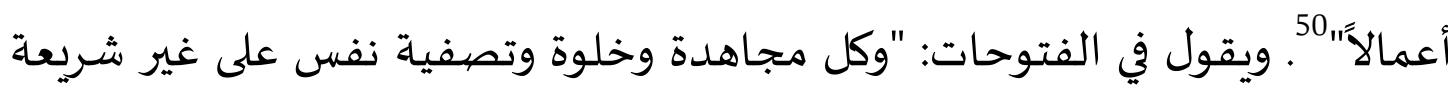

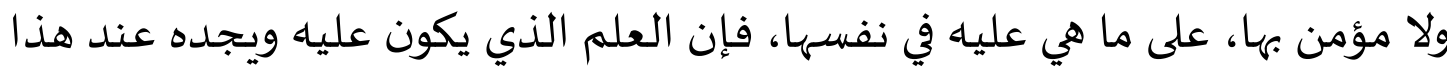

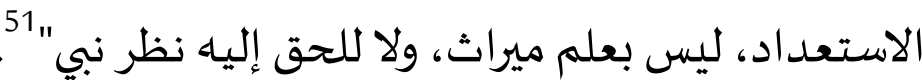

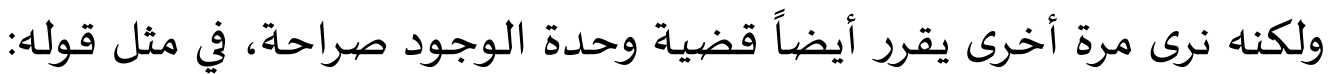
"سبحان من أظهر الأشياء وهو عينها":

$$
\begin{aligned}
& \text { يا خـالق الأشياء في نفسـهـ أنت لما تخلقه جامـع }
\end{aligned}
$$

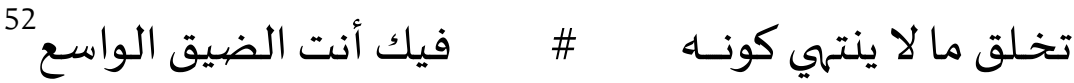

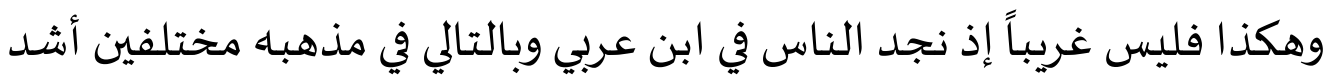

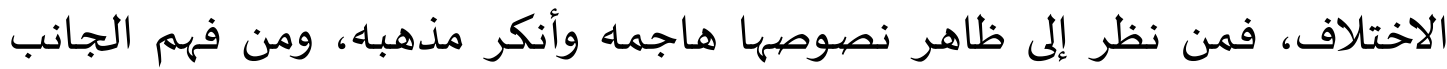
الباطني منها وأدرك مقصده وفك ألغازه شهد له بالعلم والولاية وجعل مذهباه في قمة التوحيد الذي وصل إليه العارفون بالله، ويمكن إيجاز هذه الاختلافات فيما يلي:

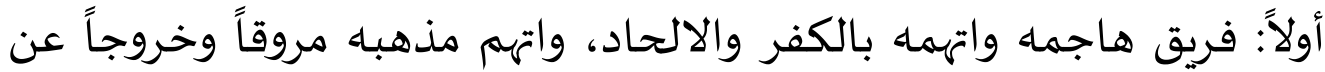

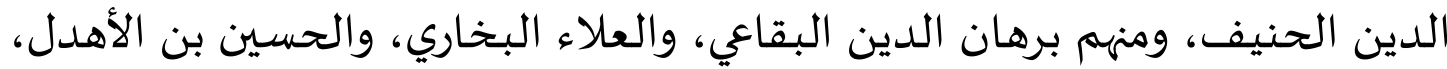

${ }^{50}$ Al-Sha'rani, Al-Yawaqit Wa Al-Jawahir, Juz 1, h. 31

51 Muhammad Ghilab, Al-Ma'rifah I'nda Muhyi Al-Din Ibn Arabi- Al-Kitab Al-Tizkari (Cairo: Dar al-Kitab al-Arabi, 1969), h. 198.

${ }^{52}$ Ibn Arabi, Fusus Al-Hikam, h. 88. 
وعباس العزاوي، 53 وابن الخياط، والحافظ الذهبي، وابن تيمية، وابن إياس،

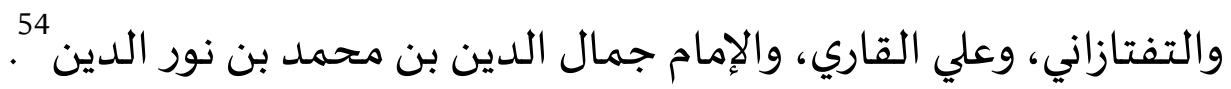
ومن هذا الفريق نجد الأهذل يضع ابن عربي ضمن الهمارل الحشوية، بل ين يعتبره

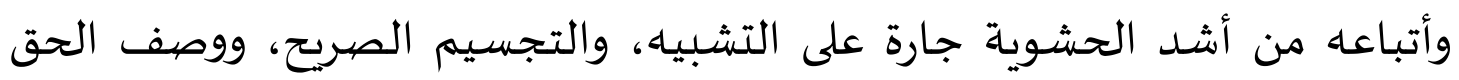

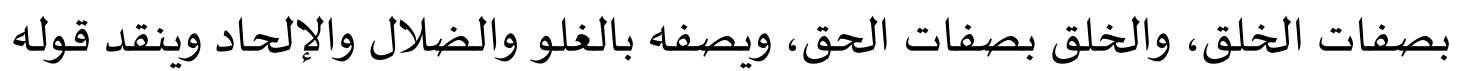
بأن العالم ليس لله وجود حقيقي بل وجودهم متوهم. ويعتبر ذلك إنكاراً من ابن عربي

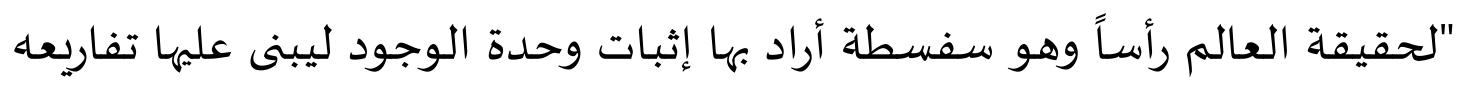
الباطلة"

وعلى الرغم من ذلك فقد رجع بعض المنكرين على ابن عربي وعلى مذهباه عن

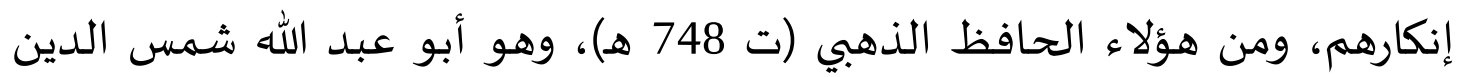

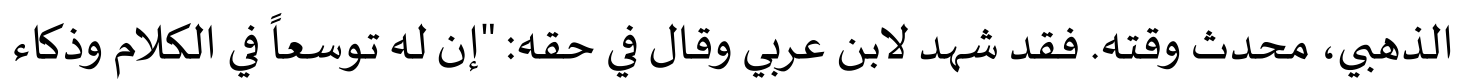

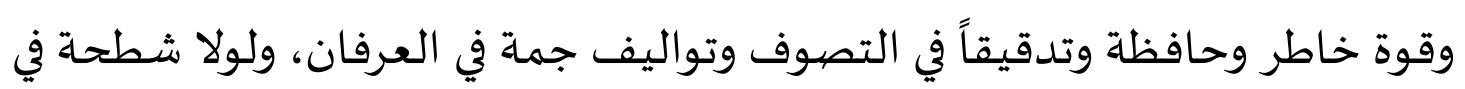

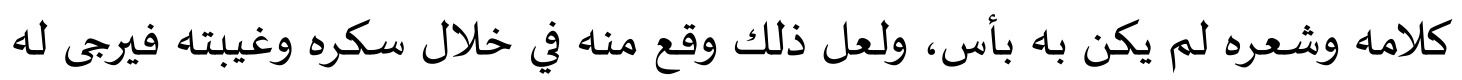

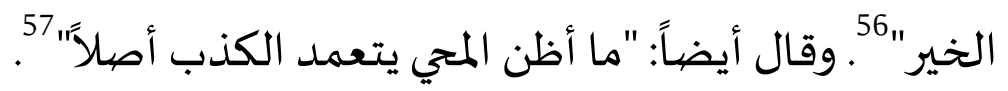

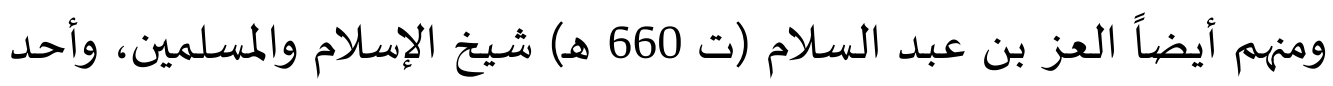

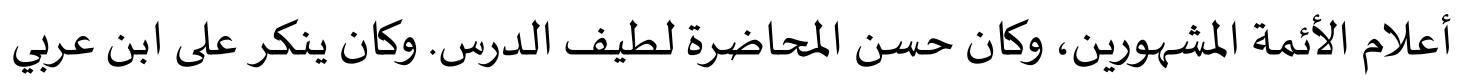
h. 50 .

${ }^{53}$ Karam Amin Abu Karam, Haqiqah Al-I'badati I'nda Ibn Arabi (Cairo: Dar al-Amin, 1997),

${ }^{54}$ Abd al-Hafiz Farghali, Ibn Arabi Sulthan Al-A'rifin (Cairo: Al-Haeah Al-Misriyah Al'Ammah Lil Kitab, 1986), h. 164.

${ }^{55}$ Al-Husain bin Abd Rahman Al-Ahdal, Kashf Al-Ghita (Tunisia: Mathba'ah al-Ittihad alAm, 1964), h. 169.

${ }^{56}$ Al-Maqqari, Nafh Al-Tib, Juz 7, h. 101.

${ }^{57}$ Al-Maqqari, Nafh Al-Tib, Juz 7, h. 146. 
في أول أمره، فلما عرف مقامه شهد له ورجع عن إنكاره وقرر: "أن محيى الدين قطب زمانه"

ثانيا: فريق دافع عنه دفاعاً حاراً، ومنهم مجد الدين الفيروزآبادي، وسراج

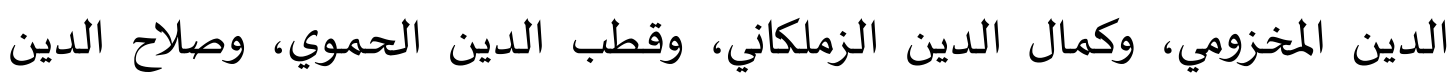

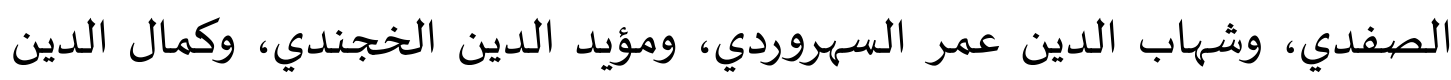

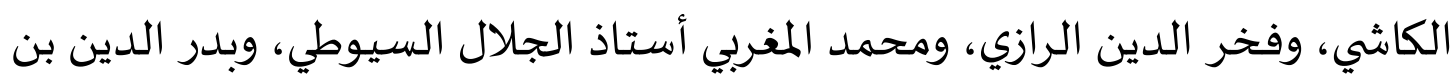

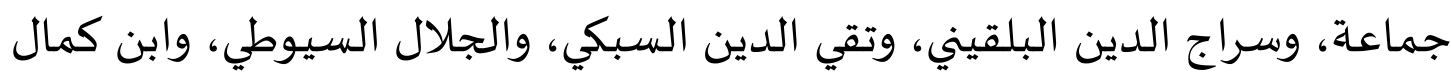
باشا، وعبد الرزاق القاشـاني وغيرهم كثير 59

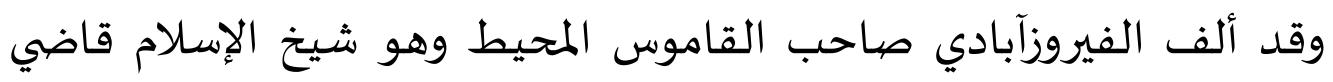
القضاة مجد الدين محمد بن يعقوب بن حمد الشيرازي الفيروزآبادي (ت 817 هـ)

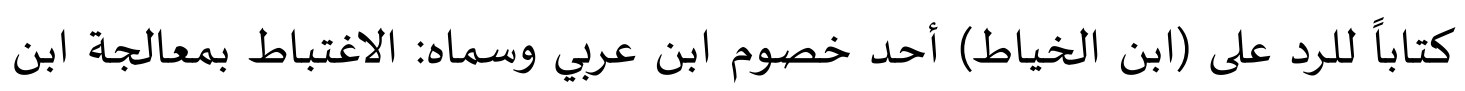

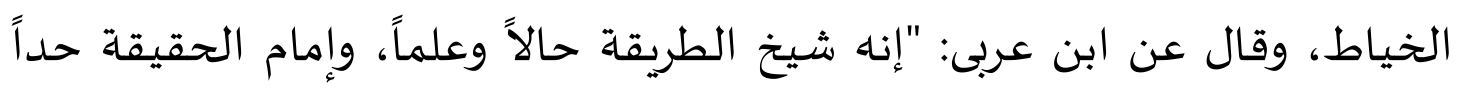
ورسماً، ومحيي رسوم المعارف فعلاً وإسماً:

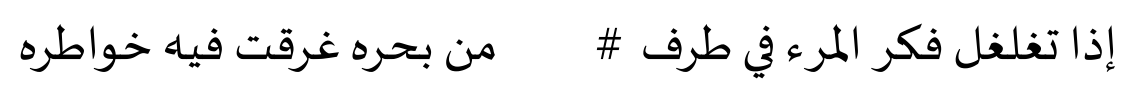

وهو عباب لا تكدره الدلاء، وسحاب لا تتقاصر عنه الأنوار، وكانت دعواته تخترق السبع الطباق، وتفترق بركاته فتملأ الآفاق" .60.

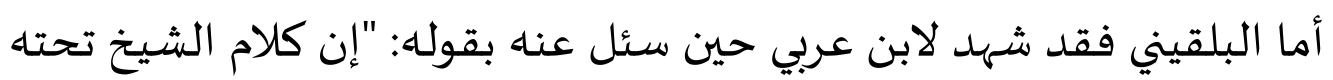
رموز وروابط وإشارات وضوابط وحذف مضافات هي في علمه وعلم أمثاله معلومة

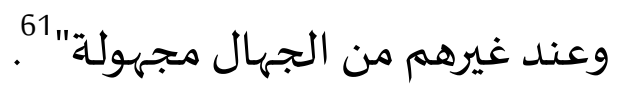

\footnotetext{
${ }^{58}$ Al-Maqqari, Nafh Al-Tib, Juz 7, h. 143.

${ }^{59}$ Farghali, Ibn Arabi Sulthan Al-A 'rifin, h. 164.

${ }^{60}$ Al-Maqqari, Nafh Al-Tib, Juz 7, h. 138.

${ }^{61}$ Al-Sha'rani, Al-Sha'rani, Al-Yawaqit Wa Al-Jawahir, Juz 2, h. 10.
} 
وممن ذكر ابن عربي بالخير أيضاً الإمام العالم بالله صفي الدين حسين بن

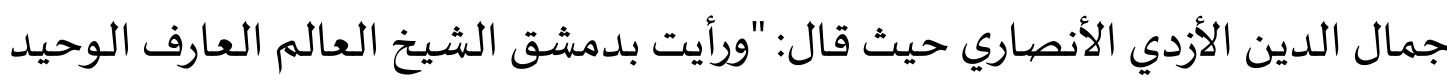

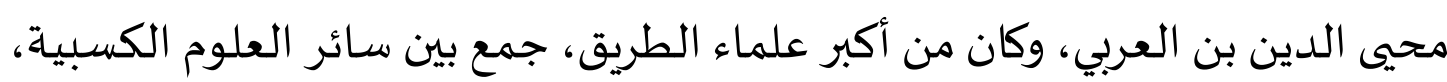

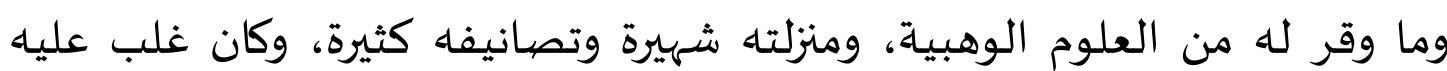

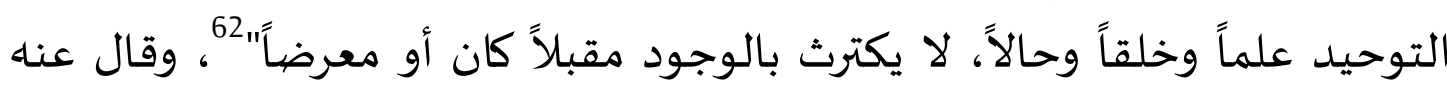

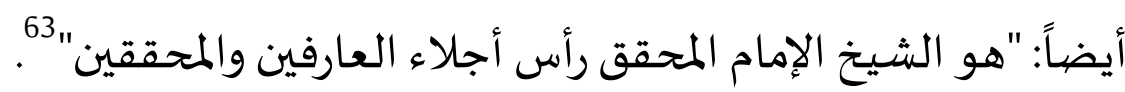

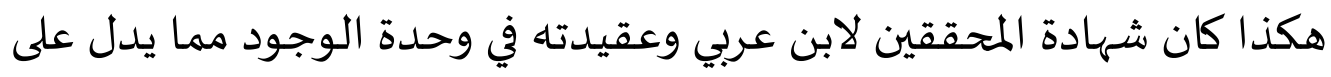

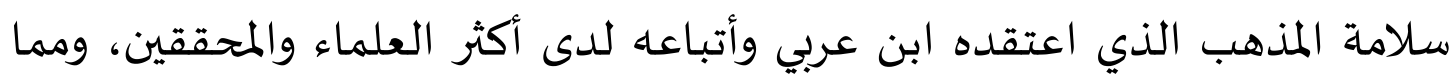

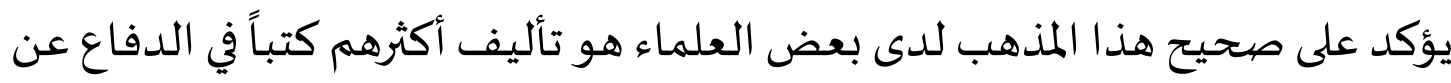

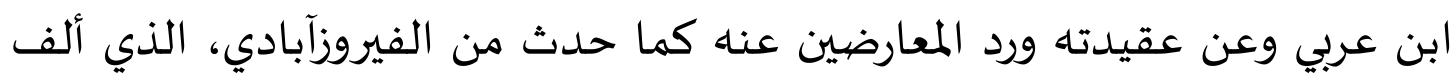

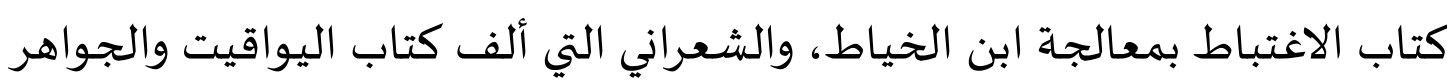
في بيان عقائد الأكابر، وجلال الدين السيوطي الذي ألف كتاب تنبياه الغبي في تبرئة النيا

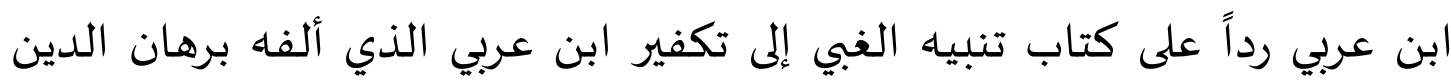

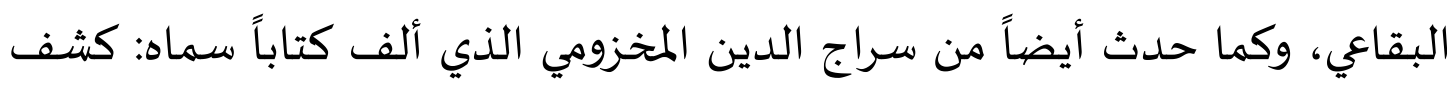

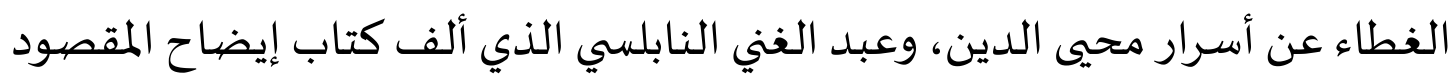

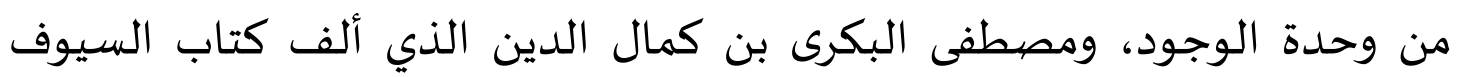

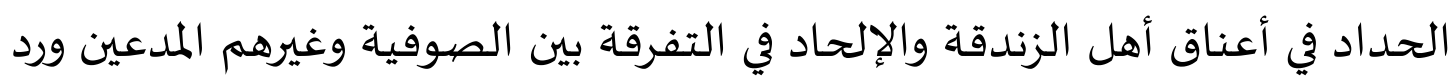
الشبهة المعترضين، وغيرذلك كثير.

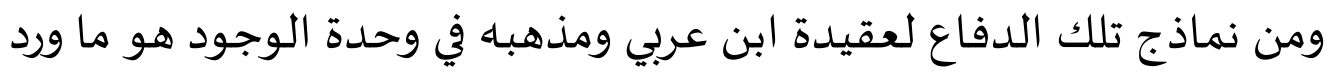
في كتاب إيضاح المقصود لعبد الغني النابلسي، حيث قال عبد الغني فيه: "إعلم أنه ليس المراد بوحدة الوجود خلاف ما عليه أئمة الإسلام، بل المراد بذلك ما اتفق عليه إبها

${ }^{62}$ Al-Maqqari, Nafh Al-Tib, Juz 7, h. 113.

${ }^{63}$ Farghali, Ibn Arabi Sulthan Al-A'rifin, h. 173. 
جميع الخاص والعام وما هو معلوم من الدين بالضرورة، من غير إنكار أصلاً من

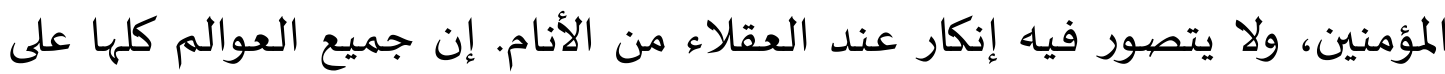

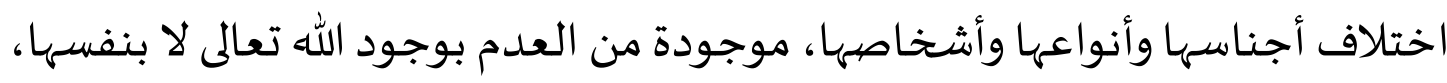

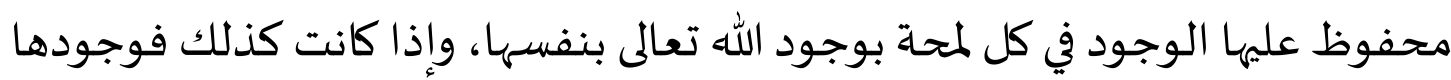
الذي هي موجودة باه في كل لمحة هو وجود الله تعالى لا وجود آخر غير وجود الله تعالى.

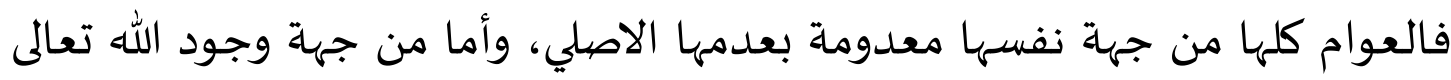

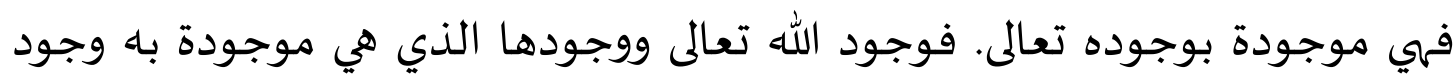

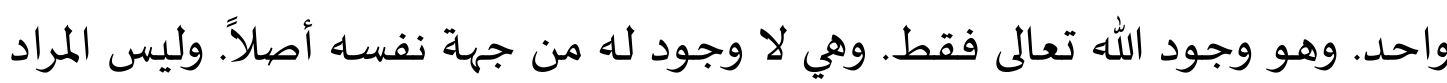

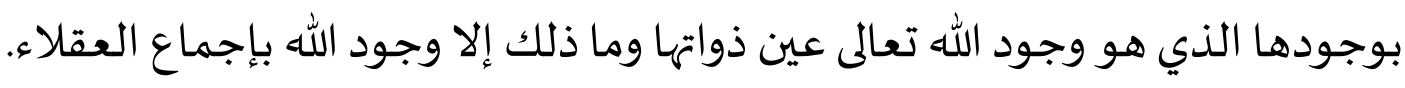

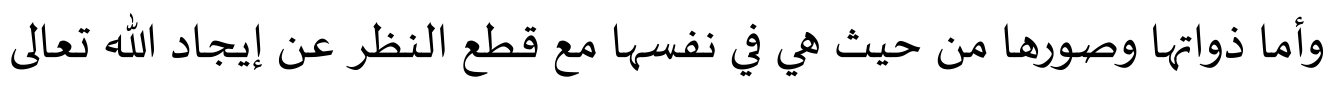
بوجوده سبحانه فلا وجود لأعينها أصلاًاء

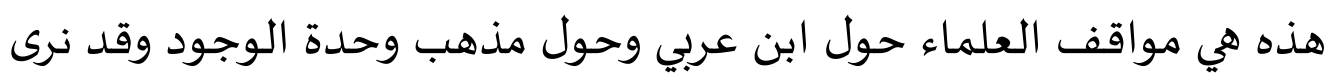

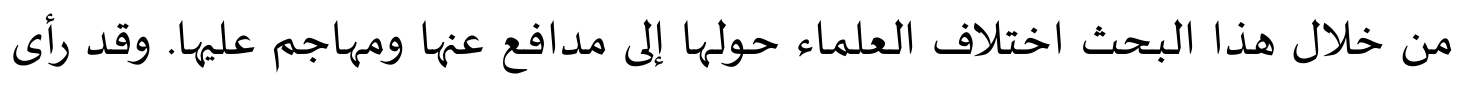

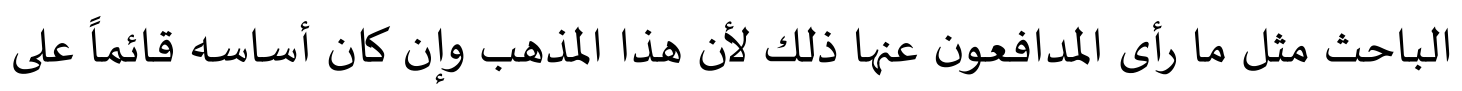

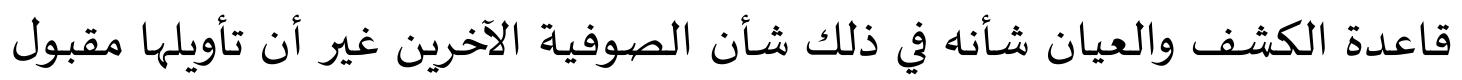

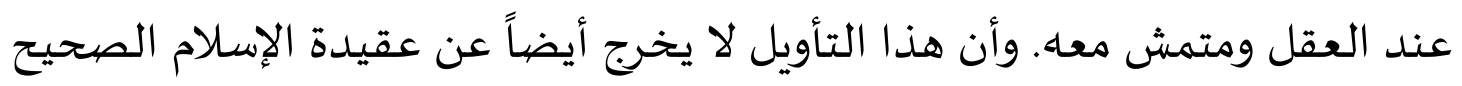
حيث أوّل بأن وحدة الوجود معناه أن الوجود الحقيقي إنما هو الله تعالى وحده وإنها

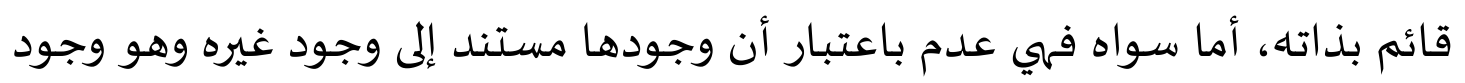
الله تعالى. ثم إن الصوفية عموماً وأصحاب مذهب وحدة الوجود خصوصاً حيث حرم

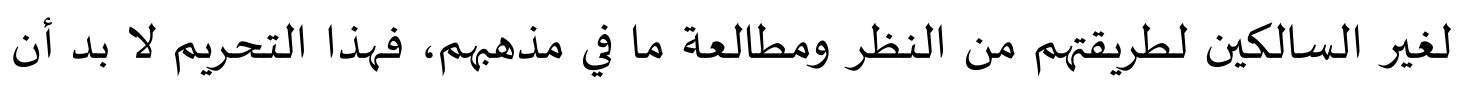

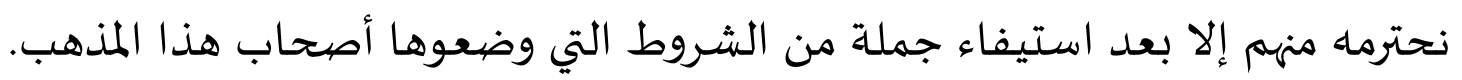

${ }^{64}$ Farghali, Ibn Arabi Sulthan Al-A'rifin, h. 59-60. 
ذلك لأنهم حيث جعلوا السلوك بما فيها من الرياضية والمجاهدة والتصفية النفسية

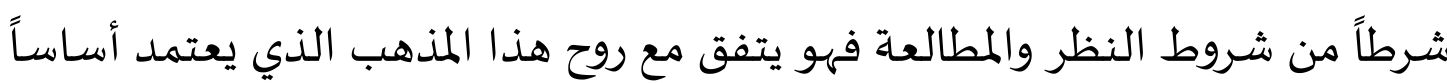

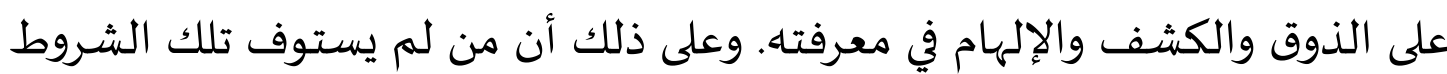
لم يستحق النظر والبحث في هذا المذهب، ذلك لأهم سوف يستخدمون المعايير

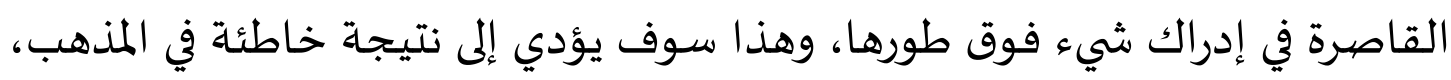
فالعقول عاجزة عن إدراك ما يدركه الأذواق والمشاعر فضهاً عن التعبير ما يدركهما.

$$
\text { د. الاستنتاج }
$$

معنى وحدة الوجود عند الصوفي إنما هو أن الوجود بأسرها حقيقة واحدة، ليس فهها ثنائية ولا تعدد، وكل ما يبدو للحواس من تعدد وكثرة في الموجودات

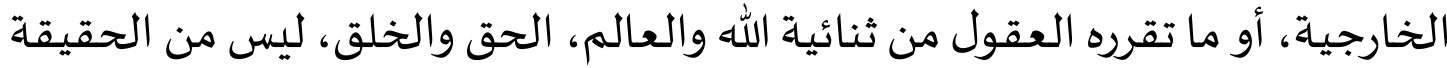

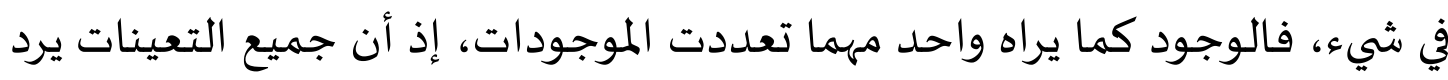
إلى عين الوحدة، فلا كثرة مع الحق بوجاه ما، لأنها هو كل شيء في في الوجوداه

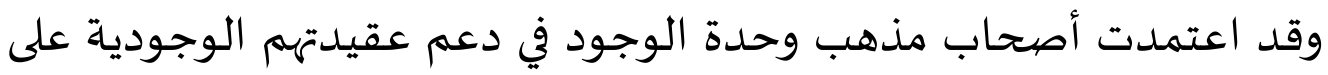

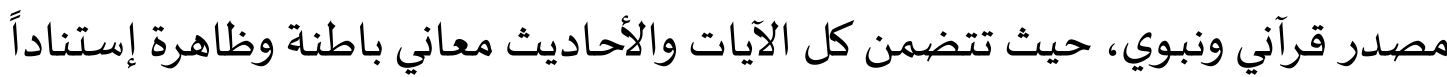

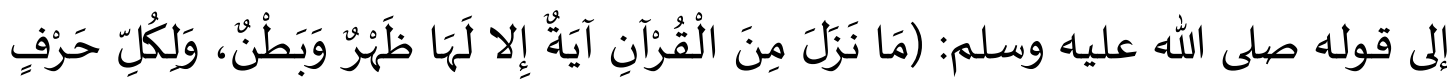

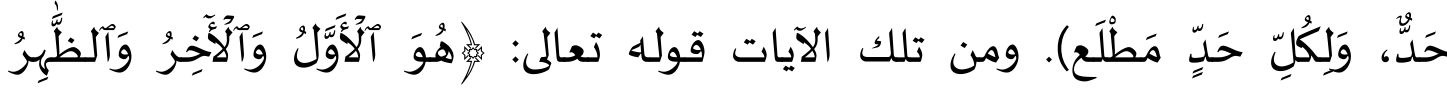

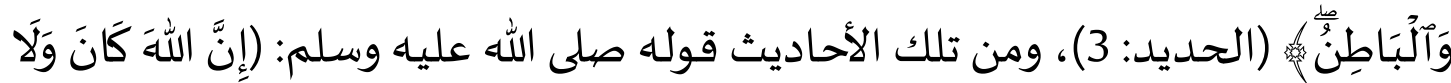
شَيْيْء مَعَاهُو.

اختلف العلماء في تقدير مذهب وحدة الوجود اختلافاً شديداً، حتى انقسموا إلى فريقين متعارضين: فريق يرى هذا المذهب يتمشى مع روح العقيدة الصحيحة

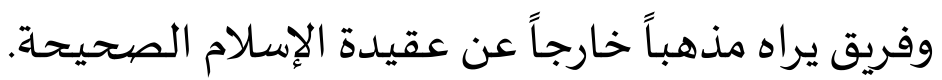


وقد رأى الباحث مثل رأى المدافعين عنها ذلك لأن هذا المذهب وإن كان أساسها

قائماً على قاعدة الكشف والعيان شأنه في ذلك شأن الصيوفية الآخرين غير أن تأويلها مقبول عند العقل ومتمش معه. وأن هذا التأويل لا يخرج أيضاً عن عقيدة الإسلام

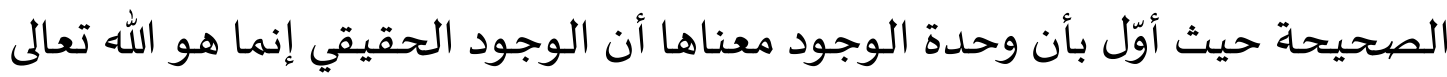

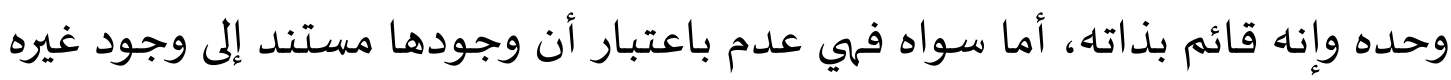
وهو وجود الله تعالى.

\section{المراجع}

Abd al-Bai'ts, Suhailah, Nazariyah Wahda Al-Wujud Baina Ibn Arabi Wa Al-Jaili (Beirut: Maktabah Khaz'al, 2002)

Abu Karam, Karam Amin, Haqiqah Al-I'badati I'nda Ibn Arabi (Cairo: Dar al-Amin, 1997)

Academy of the Arabic Language, Al-Mu'jam Al-Wajiz (Cairo: Ministry of Education, 1994)

Afifi, Abu Al-Ula, Al-Muqaddimah Wa Al-Ta'liqat A'la Fusus Al-Hikam (Beirut: Dar al-Kitab al-Arabi)

—, Ibn Arabi Fi Dirasati-Al-Kitab Al-Tizkari (Cairo: Dar al-Kitab al-Arabi, 1969)

—_, 'Majalah Turats Al-Insaniyah', Turats Al-Insaniyah, 2.1 (1962), 167

Al-'Ajami, Abul Yazid, 'Al-Tauhid Baena Al-Tasawwuf Al-Sunni Wa Al-Tasawwuf Al-Falsafi (Isyarat Wa Dilalat)', Hauliyah, 14 (1996), 99-138

Al-A'jluni, Ismail bin Muhammad, Kashf Al-Khafa Wa Muzil Al-Ilbas (Cairo: Maktabah al-Maqdisi, 1932)

Al-A'skalani, Ibn Hajar, Lisan Al-Mizan (Beirut: Dar al-Bashair al-Islamiyah, 2002) 
Al-Ahdal, Al-Husain bin Abd Rahman, Kashf Al-Ghita (Tunisia: Mathba'ah alIttihad al-Am, 1964)

Al-Bagawi, Abu Muhammad, Syarh Al-Sunnah, ed. by Syuaib Al-Arnauth and Zuhair Al-Shawish (Beirut: Al-Maktab al-Islami, 1983)

Al-Barazanji, Muhammad bin Abd al-Rasul, Al-Janib Al-Ghaibi Fi Hilli Musykilat Ibn Arabi (Damascus: Maktabah Riyadh al-Malih)

Al-Bukhari, Abu Abdillah, Al-Jami’ Al-Sahih (Beirut: Dar Tauq al-Najah, 2001)

Al-Hanbaly, Ibnul I'mad, Shadzarat Ad Dzahab Fi Akhbar Man Dzahab (Beirut: Darul Kutubil I'lmiyah, 1990)

Al-Ifrīqī, Ibn Manzur, Lisan Al-Arab (Cairo: Darul Ma’arif, 1970)

Al-Isfahani, Abu Nuaim, Hilyat Al-Awliya Wa Tabaqat Al-Ashifa (Cairo: Maktabh al-Sa'adah, 1974)

Al-Jurjany, Ali bin Muhammad, Kitab At-Ta'riifaat (Amman: Dar al-Nafais, 2003)

Al-Maqqari, Ahmad Muhammad, Nafh Al-Tib (Beirut: Darul Kutubil I'lmiyah, 1995)

Al-Nabulsi, Abd al-Ghani, Kitab Al-Wujud Wa Khitab Al-Syuhud Fi Al-Tasawwuf Wa Al-Sufiyyin (Damascus: Makhtut al-Zāāhirīyyah)

Al-Sha'rani, Abd al-Wahab, Al-Yawaqit Wa Al-Jawahir (Cairo: Maktabah Isa alBabi al-Halabi, 1959)

Farghali, Abd al-Hafiz, Ibn Arabi Sulthan Al-A'rifin (Cairo: Al-Haeah Al-Misriyah Al-'Ammah Lil Kitab, 1986)

Ghilab, Muhammad, Al-Ma'rifah I'nda Muhyi Al-Din Ibn Arabi- Al-Kitab AlTizkari (Cairo: Dar al-Kitab al-Arabi, 1969)

Ibn Arabi, Muhyi al-Din, Al-Futuhat Al-Makkiyah (Cairo: Mathba'ah Bolaq)

—, Al-Futuhat Al-Makkiyah, ed. by Utsman Yahya (Cairo: Al-Haeah AlMisriyah Al-'Ammah Lil Kitab, 1985)

—, Fusus Al-Hikam, ed. by Abu Al-Ula Afifi (Beirut: Dar al-Kitab al-Arabi)

—, Tafsir Al-Qur'an Al-Karim (Beirut: Dar al-Yaqzah al-Arabiyah, 1968)

Ṣalībā, Jamīl, Al-Mu’jam Al-Falsafi (Beirut: Dar Al-Kitab Al-Lubnani, 1971)

Sayyid al-Ahl, Abd al-Aziz, Muhyi Al-Din Ibn Arabi Min Syi'rih (Beirut: Dar alI'lmi Lilmalayin, 1970) 


\section{Guidelines}

\section{Submission of Article}

urnal Adabiyah welcomes the articles submission with the main themes on Humanities and Islamic Studies with the emphasis on interdisciplinary and intertextuality approach. Adabiyah is thematicly published twice in a year. ie the theme of the humanities in June and the Islamic Study in December.

Themes related to Islamic Studies are textual studies, scriptural traditions, Islamic law, and theology; and those related to Humanities are language, literature, history, and culture. This scholarly journal Guarantees that the editor decision based on the peer review results will not exceed 30 days from the paper submission date.

Authors are invited to read our archives; to find the relevant topics for the journal, and to submit complete unpublished scientific researches, which are not under review in any other conferences or academic journal.

\section{PUBLICATION ETHIC}

Publication Ethic and Malpractice Statement

Jurnal Adabiyah is a peer-reviewed journal, published twice a year by the Faculty of Adab and Humaniora, Alauddin State Islamic University of Makassar Indonesia. It is available online as open access sources as well as in print. This statement clarifies ethical behaviour of all parties involved in the act of publishing an article in this journal, including the author, the editor-in-chief, the Editorial Board, the reviewers, and the publisher. This statement is based on COPE's Best Practice Guidelines for Journal Editors.

Ethical Guideline for Journal Publication

The publication of an article in Jurnal Adabiyah, is an essential building block in the development of a coherent and respected network of knowledge. It is a direct reflection of the quality of the work of the authors and the institutions that support them. Peer-reviewed articles support and embody the scientific methods. It is therefore important to agree upon standards of expected ethical behavior for all parties involved in the act of publishing: the author, the editor, the reviewer, the publisher, and the society. As the publisher of Jurnal Adabiyah, the Faculty of Adab and Humaniora takes its duties of guardianship over all stages of publishing seriously and it recognizes its ethical and other responsibilities. The Faculty of Adab and Humaniora committed to ensuring that advertising, reprint or other commercial revenue has no impact or influence on editorial decisions.

\section{Publication Decisions}

The editors of Jurnal Adabiyah is responsible for deciding which articles submitted to the journal should be published. The validation of the work in question and its importance to researchers and readers must always drive such decisions. The editors may be guided by the policies of the journal's editorial board and constrained by such legal requirements as shall then be in force regarding libel, copyright infringement, and plagiarism. The editors may confer with other editors or reviewers in making their decisions.

\section{Plagiarism Screening}

It is basically author's duty to only submit a manuscript that is free from plagiarism and academically malpractices. The editor, however, will check all submitted papers through Turnitin.

\section{Fair Play}

An editor at any time evaluates manuscripts for their intellectual content without regard to race, gender, sexual orientation, religious belief, ethnic origin, citizenship, or political philosophy of the authors. 


\section{Confidentiality}

The editors and any editorial staff must not disclose any information about a submitted manuscript to anyone other than the corresponding author, reviewers, potential reviewers, other editorial advisers, and the publisher, as appropriate.

\section{Disclosure and Conflicts of Interest}

Unpublished materials disclosed in a submitted manuscript must not be used in editors' own research without the express written consent of the author.

\section{DUTIES OF AUTHORS}

\section{Reporting Standards}

Authors of reports of original research should present an accurate account of the work performed as well as an objective discussion of its significance. Underlying data should be represented accurately in the paper. A paper should contain sufficient detail and references to permit others to replicate the work. Fraudulent or knowingly inaccurate statements constitute unethical behaviour and are unacceptable.

\section{Originality and Plagiarism}

The authors should ensure that they have written entirely original works, and if the authors have used the work and/or words of others that this has been appropriately cited or quoted.

\section{Multiple, Redundant, or Concurrent Publication}

An author should not in general publish manuscripts describing essentially the same research in more than one journal or primary publication. Submitting the same manuscript to more than one journal concurrently constitutes unethical publishing behaviour and is unacceptable.

\section{Acknowledgement of Sources}

Proper acknowledgment of the work of others must always be given. Authors should cite publications that have been influential in determining the nature of the reported work.

\section{Authorship of the Paper}

Authorship should be limited to those who have made a significant contribution to the conception, design, execution, or interpretation of the reported research. All those who have made significant contributions should be listed as co-authors. Where there are others who have participated in certain substantive aspects of the research project, they should be acknowledged or listed as contributors. The corresponding author should ensure that all appropriate co-authors and no inappropriate co-authors are included on the paper, and that all co-authors have seen and approved the final version of the paper and have agreed to its submission for publication.

\section{Disclosure and Conflicts of Interest}

All authors should disclose in their manuscript any financial or other substantive conflict of interest that might be construed to influence the results or interpretation of their manuscript. All sources of financial support for the project should be disclosed.

\section{Fundamental errors in Published Works}

When an author discovers a significant error or inaccuracy in his/her own published work, it is the author's obligation to promptly notify the journal editor or publisher and cooperate with the editor to retract or correct the paper.

\section{PLAGIARISMIE}

It is basically author's duty to only submit a manuscript that is free from plagiarism and academically malpractices. The editor, however, will check all submitted papers through Turnitin. 


\section{AUTHOR GUIDELINES}

\section{Guidelines for online submission:}

1. Author should first register as Author to the website of Jurnal Adabiyah. Click the menu "register" to register as an author.

2. Once after the author is registered, please login to the website of Jurnal Adabiyah and submit the article through online submission (with the stat us of active submissions).

3. The article should follow the standard template of Jurnal Adabiyah provided in the website.

4. The citation and bibliography should follow the Turabian citation style.

5. Author is restricted not to send his/her article to another journal before having confirmation from the editorial team (approximately 4 weeks right after the article submitted).

6. Author should follow editorial decisions and recommendations related to the article completion. All reviews and assessements will be informed through online submission.

Article submitted to Jurnal Adabiyah editorial board must follow these guidelines:

1. Article should be based on the scientific research in the field humanities and Islamic studies;

2. Article must be an original work and has not been previously published;

3. Article should be written in Arabic or English languages;

4. Article must be typed in one-half spaced on A4-paper size;

5. Article's length is about $6,000-10,000$ words;

6. All submission must include a 150-250 word abstract;

7. Abstract should be written in 3 languages; Arabic, English, and Bahasa;

8. Full name(s) of the author(s) must be stated, along with his/her/their institution and complete address;

9. All submission should be in OpenOffice, Microsoft Word, RTF, or WordPerfect document file format;

10. Bibliographical reference must be noted in footnote and bibliography according to Jurnal Adabiyah style. In addition, it is suggested for author(s) to use reference manager tools such

\section{as MENDELEY or 7 otero}

When a source is cited for the first time, full information is provided: full name(s) of author(s), title of the source in italic, place of publication, publishing company, date of publication, and the precise page that is cited. For the following citations of the same source, list the author's last name, two or three words of the title, and the specific page number(s). The word ibid., op.cit., and loc.cit. are may not be used any more.

\section{Example in footnotes:}

${ }^{1}$ Mircea Eliade (ed.), The Encyclopedia of Religion, vol. 8 (New York: Simon and Schuster, 1995), h. 18.

${ }^{2}$ Norman Daniel, Islam and the West (Oxford: One World Publications, 1991), h. 190.

${ }^{3}$ Syeikh Ja'far Subhāni, Mafăhim Al-Qur'ān (Beirut: Mu'assasah Al-Tarīkh Al-'Arabī, 2010)., Juz 5, h. 231. 
${ }^{4}$ Syeikh Ja'far Subhānī, Mafāhim Al-Qur'ān, h. 8-9.

\section{Example in bibliography:}

Subhānī, Syeikh Ja'far. Mafăhim Al-Qur'ān. Beirut: Mu'assasah Al-Tarīkh Al-’Arabī, 2010.

Eliade, Mircea (ed.). The Encyclopedia of Religion, vol. 8. New York: Simon and Schuster, 1995.

Daniel, Norman. Islam and the West. Oxford: One World Publications, 1991.

Shihab, Muhammad Quraish. Sunnah-Syiah Bergandengan Tangan: Mungkinkah? Kajian Atas Konsep Ajaran Dan Pemikiran. Cet. III. Jakarta: Lentera Hati, 2007.

\section{Detail informations of the footnotes:}

1. Holy book

Al-Qur'ân, Al-Baqarah/2: 185.

Perjanjian Baru, Mrk. 2: 18.

2. Qur'anic translation

${ }^{1}$ Departemen Agama RI, al-Qur'an dan Terjemahannya (Jakarta: Darus Sunnah, 2005), h. 55.

3. Book

${ }^{1}$ Muḥammad 'Ajjaj al-Khațib, Ușl al-Hadith: 'Ulumuh wa Mușțalaḥ uh (Beirut: Dâr al-Fikr, 1989), h. 57.

4. Translation Books

${ }^{1}$ Toshihiko Izutsu, Relasi Tuhan dan Manusia: Pendekatan Semantik terhadap al-Qur'an, terj. Agus Fahri Husein dkk (Yogyakarta: Tiara Wacana, 2003), h. 14.

5. Voluminous book

${ }^{1}$ Muḥammad al-Ṭâhir b. 'Ashur, al-Tahrīir wa al-Tanwīr, Vol. 25 (Tunisia: Dâr al-Suhûn, 2009), h. 76.

${ }^{1}$ Muḥammad b. Ismā‘īl al-Bukharī, al-Jami‘ al-Ṣaḥịh, Vol. 2 (Beirut: Dar al-Kutub al-‘Ilmı́yah, 1999), h. 77.

6. Article in book

${ }^{1}$ Sahiron Syamsuddin, "Metode Intratekstualitas Muhammad Shahrur dalam Penafsiran al-Qur'an" dalam Abdul Mustaqim dan Sahiron Syamsuddin (eds.), Studi al-Qur'an Kontemporer: Wacana Baru Berbagai Metodologi Tafsir (Yogyakarta: Tiara Wacana, 2002), h. 139.

7. Article in encyclopaedia

${ }^{1}$ M. Th. Houtsma, "Kufr" dalam A. J. Wensinck, at al. (ed.), First Encyclopaedia of Islam, Vol. 6 (Leiden: E.J. Brill, 1987), h. 244.

8. Article in journal

${ }^{1}$ Muhammad Adlin Sila, "The Festivity of Maulid Nabi in Cikoang, South Sulawesi: Between Remembering and Exaggerating the Spirit of Prophet", Studia Islamika 8, no. 3 (2001): h. 9.

9. Article in mass media

${ }^{1}$ Masdar F. Mas'udi, "Hubungan Agama dan Negara”, Kompas, 7 Agustus 2002. 
10. Article in Internet

${ }^{1}$ Muhammad Shahrūr, "Reading the Religious Teks: a New Approach" dalam http://www.shahrour.org/25 Februari 2010/diakses 5 Juni 2010.

11. Thesis or dissertation

${ }^{1}$ Syahruddin Usman, "KinerjaGuru Penddikan Agama Islam pada SMAN dan SMKN Kota Makassar”, Disertasi (Makassar: PPs UIN Alauddin, 2010), h. 200.

\section{COPYRIGHT NOTICE}

Authors who publish with this journal agree to the following terms:

1) Authors retain copyright and grant the journal right of first publication with the work simultaneously licensed under a Creative Commons Attribution License that allows others to share the work with an acknowledgement of the work's authorship and initial publication in this journal.

2) Authors are able to enter into separate, additional contractual arrangements for the non-exclusive distribution of the journal's published version of the work (e.g., post it to an institutional repository or publish it in a book), with an acknowledgement of its initial publication in this journal.

3)Authors are permitted and encouraged to post their work online (e.g., in institutional repositories or on their website) prior to and during the submission process, as it can lead to productive exchanges, as well as earlier and greater citation of published work (See The Effect of Open Access). 